\title{
T-LYMPHOCYTE INTERACTIONS WITH ENDOTHELIUM AND EXTRACELLULAR MATRIX
}

\author{
Stephen W. Hunt III \\ Division of Immunopathology, Worner-Lambert/Parke-Davis Pharmaceutical Research Division, Ann Arbor, MI 48105 \\ Estelle S. Harris \\ Division of Pulmonary and Critical Care, Department of Internal Medicine, University of Michigan Medical School, Ann Arbor, Ml 48109 \\ Sirid-Aimée Kellermann \\ Yoï Shimizu* \\ Department of Laboratory Medicine and Pathology and Center for Immunology, University of Minnesoto Medical School, Box 609 UMHC, 420 Delaware St., SE, Minneapolis, MN 55455; "to \\ whom correspondence and reprint requests should be addressed
}

\begin{abstract}
T-lymphocyte movement out of the bloodstream and into tissue is critical to the success of these cells in their role in immunosurveillance. This process involves interactions of the T-cell with endothelium as well as with extracellular matrix. Central to these interactions are a number of T-cell adhesion molecules and their endothelial and extracellular matrix ligands. The identification and functional characterization of adhesion molecules have been the subject of intensive research in recent years. We highlight here the latest developments in this rapidly expanding field as they pertain to T-cell interactions with endothelial cells and extracellular matrix components, including: (1) identification of adhesion molecule families, including the selectins, mucins, integrins, immunoglobulin superfamily members, and cadherins; (2) elucidation of the multi-step adhesion cascade that mediates the rolling, arrest, and eventual diapedesis of T-cells through the vascular endothelium into the surrounding tissue; (3) the changes in adhesion molecule expression that accompany T-cell maturation and activation, and the impact of those changes on T-cell migration; (4) the functional relevance of the extracellular matrix for T-cell function; and (5) the clinical relevance of adhesion molecules and the potential for targeting these molecules for the amelioration of immune-mediated diseases
\end{abstract}

Key words. Cell adhesion, integrin, selectin, extracellular matrix, endothelium

\section{(I) Introduction}

A dhesion receptors allow circulating leukocytes to initiate physical contact with the extracellular environment and to respond appropriately to information found in that environment. For T-lymphocytes, this requirement for adhesion can be broken down conceptually into two components. First, T-cells respond to foreign antigen only when peptides derived from that antigen are associated with an appropriate major histocompatibility (MHC) antigen and are recognized by the antigen-specific T-cell receptor. Therefore, T-cell function requires the physical interaction of $\mathrm{T}$-cells with antigen-presenting cells. Adhesion receptors such as the lymphocyte function-associated antigen-1 (LFA-1) integrin and the CD2 antigen, as well as others, have been shown to play essential roles in T-cell interactions with antigen-presenting cells. Second, T-cells continuously circulate throughout the body in order to maximize the chances that the rare T-cell expressing a T-cell receptor with the appropriate specificity encounters the peptide/MHC combination that leads to the signal transduction events that result in T-cell activation, proliferation, and effector functions. Changes in adhesion molecule expression that occur as a result of an encounter with antigen permanently alter the recirculation pattern of the resulting memory T-cells. Furthermore, the process of inflammation results in the active and specific recruitment of $\mathrm{T}$ cells and other leukocytes into the inflammatory site

The critical cell-cell interaction mediating the specificity of T-cell recirculation and recruitment is the adhesion of circulating T-cells with vascular endothelial cells (EC). Recent advances in our understanding of this adhesive interaction have illustrated the sequential involvement of different adhesion molecules as well as a critical activation step, providing for considerable complexity and regulatory flexibility. Although not as extensively appreciated, components of the extracellular matrix (ECM) also play a vital role in both T-cell recognition of antigen and T-cell recirculation and recruitment. This review highlights recent insights into lymphocyte interactions with endothelium and ECM, with a specific 


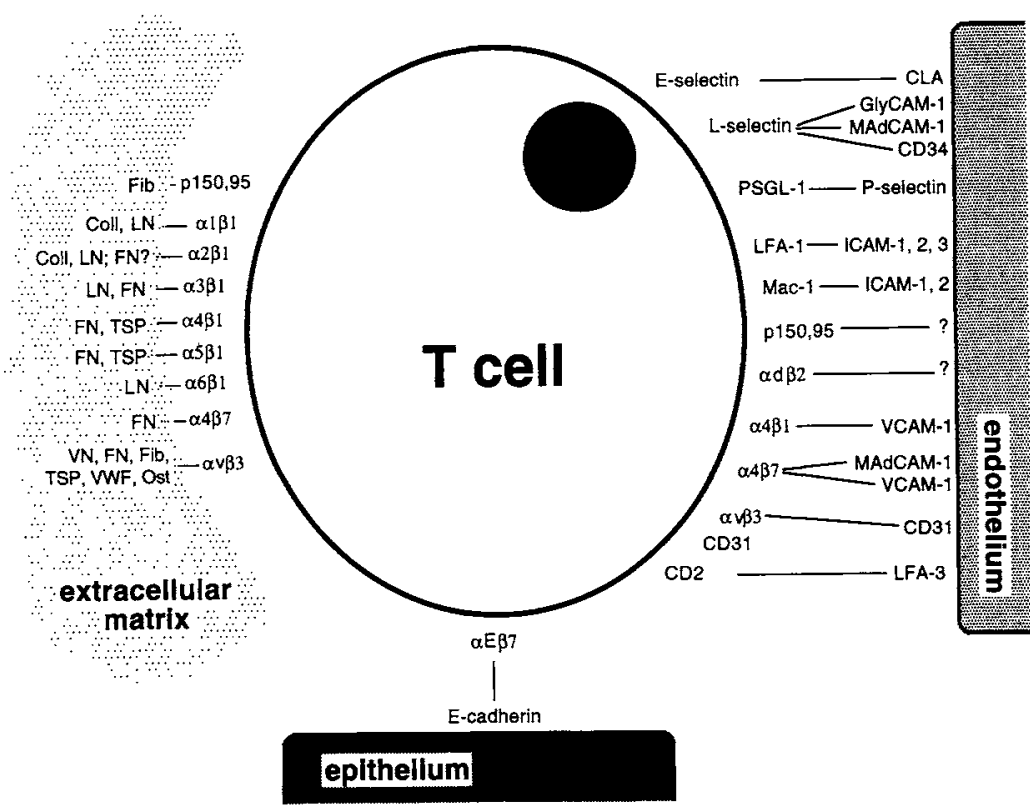

Figure 1. Adhesion molecules and their ligands. Known receptor-ligand interactions mediating T-cell adhesion to endothelium, epithelium, and extracellular matrix are indicated. This figure illustrates the vast number of adhesion molecules utilized by T-cells, but is not meant to indicate that any specific T-cell expresses and/or utilizes all of these adhesion receptors. FN, fibronectin; Fib, fibrinogen; Coll, collagen; LN, laminin; VN, vitronectin; TSP, thrombospondin; WWF, von Willebrand's factor; Ost, osteopontin.

emphasis on T-lymphocytes. We have attempted to focus on: (1) novel adhesion molecules involved in T-cell interactions with endothelium and ECM; (2) the dynamics of the adhesion cascade mediating T-cell adhesion to ECs; (3) changes in adhesion molecule expression upon peripheral T-cell differentiation; and (4) the concept that the ECM represents a rich milieu of information to which the $\mathrm{T}$-cell responds during both T-cell migration and recognition of antigen. We regret that space constraints prevent us from adequately citing all of the seminal contributions by investigators in this field. In most of the sections that follow, we have cited many other outstanding reviews that have treated these specific areas in more detail than was possible here.

\section{(II) Families of Adhesion Molecules}

There are five structural families of adhesion molecules that have been described to date: the selectins, the mucins, the integrins, the immunoglobulin superfamily (IgSF), and the cadherins. These families are utilized by T-cells to interact with endothelium, epithelium, and ECM components (Fig. 1).

\section{(A) Selectins}

The selectins are a group of cell-surface glycoproteins found on endothelium, platelets, and leukocytes (reviewed in Carlos and Harlan, 1994; Lasky, 1995; Tedder et al., 1995). The selectins are the only family of structural adhesion molecules whose single known purpose is to mediate leuko-
cyte-EC interactions. The selectins are important in several aspects of lymphocyte-endothelial interactions, including the initial intravascular arrest of circulating lymphocytes and subsequent rolling on intravascular ECS. The three-member family includes E-selectin (CD62E, ELAM-1), P-selectin (CD62P, GMP-140), and L-selectin (CD62L). Similar in structure, the selectins are made up of an $\mathrm{N}$-terminal C-type lectin-like domain, an epidermalgrowth-factor-like domain, a variable number of consensus sequences (similar to complement-regulatory proteins), a membrane spanning sequence, and a short cytoplasmic tail

Although structurally similar, the three selectin family members show differences with respect to their tissue distribution and regulation (reviewed in Carlos and Harlan, 1994). Eselectin is expressed primarily on activated EC and binds to ligands expressed on neutrophils, monocytes, basophils, and a subset of $\mathrm{CD}^{+}$ memory T-cells. E-selectin is transcriptionally up-regulated by multiple stimuli, including interleukin (IL)- 1 , tumor necrosis factor (TNF)- $\alpha$, and lipopolysaccharide (LPS) (Carlos and Harlan, 1994). P-selectin is expressed on platelets and activated endothelium, and binds ligands expressed on neutrophils, monocytes, and a minority of $\mathrm{CD}^{+}$memory T-cells. P-selectin is stored and synthesized in granules $(\alpha$ granules in platelets and Weibel-Palade bodies in EC), and up-regulation can occur in minutes after exposure to many stimuli, including thrombin, histamine, and cytokines (Carlos and Harlan, 1994). L-selectin was initially identified as being important in lymphocyte binding to high endothelial venules (HEV), which are specialized postcapillary venules of lymphoid tissue. When the Mel-14 monoclonal antibody (mAb) was used in mice, L-selectin was implicated as a homing receptor involved in lymphocyte migration into peripheral lymph nodes (PLN) (reviewed in Lasky, 1995). Subsequently, L-selectin was found to be expressed on most peripheral blood leukocytes. Unlike the other selectins, L-selectin is constitutively expressed on the cell surface, and can be shed after activation by protease cleavage near the membrane insertion site (Lasky, 1995; Tedder et al., 1995). L-selectin cleavage has been speculated to allow for lymphocyte detachment and possible attenuation of the immune response. In support of this hypothesis, soluble L-selectin in vitro has been shown partially to inhibit leukocyte adhesion to cytokine-stimulated endothelium (McEver, 1994).

To date, several heavily glycosylated proteins containing O-linked carbohydrate side-chains have been identified as physiologic ligands for the selectins, including glycosylation-dependent cell adhesion molecule-1 (GlyCAM-1, Sgp50), CD34 (Sgp90), mucosal-addressin 
cell adhesion molecule-1 (MAdCAM-1), P-selectin glycoprotein ligand-1 (PSGL-1), and cutaneous lymphocyte antigen (CLA) (see below). Selectins bind simple carbohydrate moieties on their ligands via a calcium-dependent interaction with the lectin domain in a unique protein-nonprotein interaction. One of the first selectin carbohydrate ligands to be identified was the small fucosylated tetrasaccharide, sialyl Lewis $X\left(\right.$ SLe $\left.^{x}\right)$. SLe ${ }^{x}$ | NeuNaco2.3Gal $\alpha 1,4$ (Fuc $\alpha 1,3$ )GlCNAc, where Nac = sialic acid, Gal $=$ galactose, Fuc $=$ fucose, and GlcNAc $=\mathrm{N}$ acetyl glucosaminel is thought to be the minimal oligosaccharide needed for selectin-mediated adhesion. SLe ${ }^{\mathrm{x}}$ binds all three selectins with low, but differing, affinities (McEver, 1994; Lasky, 1995). Nonetheless, SLe ${ }^{x}$ has been shown to mediate lymphocyte adhesion to HEV in frozen sections of lymph node (LN) tissue by means of the Stamper-Woodruff HEV binding assay. The relevance of selectins to leukocyte interactions with endothelium is illustrated by the recent identification of a clinical syndrome. leukocyte adhesion deficiency type II (LAD type II). Patients with LAD type II suffer from a generalized defect in fucose metabolism that results in a lack of SLe ${ }^{\mathrm{x}}$ expression. Consequently, neutrophils from LAD type II patients fail to bind either E-selectin or P-selectin expressed on endothelial cells (Price et al., 1994). The clinical manifestations of LAD type II are similar to those described for LAD (see below).

\section{(B) Mucins}

Mucins are glycoproteins containing primarily O-linked carbohydrate side-chains attached to serine or threonine residues (reviewed in Shimizu and Shaw. 1993; Lasky, 1995). Mucins are one of the newest families of adhesion molecules to be identified, and there is considerable speculation that many family members are yet to be found. Three mucins have been identified as selectin ligands: GlyCAM-1, CD34, and MAdCAM-1

GlyCAM-1 -a mucin-like glycoprotein with two sulfated, sialylated, and fucosylated heavily O-linked oligosaccharide chains-is expressed on PLN HEV and hematopoietic progenitors, and binds L-selectin. GlyCAM-1 lacks a conventional transmembrane region and is uniquely anchored to the EC surface by an incompletely defined mechanism. It is thought that GlyCAM-1 is shed as a potentially soluble protein (Shimizu and Shaw, 19931, although the physiological significance of this shed molecule is not yet understood. Recently, a sulfated SLe - like core of GlyCAM-1, $\left(\mathrm{SO}_{4}-6\right) \mathrm{Gal}$ ( 1 -4GlcNAC, was identified and may serve as the selectin recognition determinant on GlyCAM-1 (Hemmerich et al., 1994).

CD34 is a sialomucin-like protein ligand for Lselectin that is widely expressed intravascularly. Using an anti-CD34 mAb, Baumhueter et al. (1994) demonstrated intravascular staining in all lymphoid and non-lymphoid organs in mice. Although CD34 expression was main- tained at sites of inflammation, no changes in expression levels were noted immunohistologically. Based on the ubiquitous expression of CD34, even in mature PLN, where L-selectin-mediated lymphocyte-endothelial binding does not occur, the authors speculated that changes in CD34-mediated binding to L-selectin are regulated by differential glycosylation of the carbohydrate moieties (Baumhueter et al., 1994)

MAdCAM-1 is a $58-66-k$ Da protein initially identified as the mucosal addressin recognized by the MAb MECA367 (reviewed in Carlos and Harlan, 1994). MAdCAM-I is expressed primarily on Peyer's patch HEV, mesenteric LN HEV, and mucosal lamina propria venules (Picker, 1994). MAdCAM-1 is a novel protein containing both a mucinlike domain, that is capable of binding L-selectin, and an IgSF-like domain, that is capable of binding $\alpha 4 \beta 7$ (Berg et al., 1993). Thus, MAdCAM-1 can support both lymphocyte rolling and integrin-mediated adhesion.

Additional members of the mucin family that are expressed on lymphocytes and are important in lymphocyte-endothelial interactions include the P-selectin glycoprotein ligand, PSGL-I, and the E-selectin ligand, CLA (Shimizu and Shaw, 1993; Picker, 1994). PSGL-1 is found on the surfaces of myeloid cells and activated lymphocytes. CLA is selectively expressed on memory T-cells that migrate to the skin (see below). Both of these molecules contain a dense network of O-linked carbohydrate chains. These long side-chains are predicted to bear a heavy negative charge, but are long enough to help the ligand gain exposure above the glycocalyx of the cell membrane. Thus, only in specific cell-cell interactions, where the apposing cell has the specific selectin-ligand receptors, will these negative charges be overcome and adhesion ensue (Shimizu and Shaw, 1993)

\section{(C) INTEGRINS}

The integrins are a large family of cell-surface proteins, expressed as $\alpha \beta$ heterodimers, that mediate cell-cell and cell-ECM interactions (reviewed in Carlos and Harlan. 1994; Diamond and Springer, 1994). The integrins are important in the regulation of many cellular functions, including embryonic development, tumor invasion and metastasis, wound healing, and the immune response. There have been $15 \alpha$ chains and $8 \beta$ chains identified to date, giving rise to at least $2 \mathrm{I}$ different noncovalently bound $\alpha \beta$ combinations. The $\alpha$ subunits, which vary in size from $120-180 \mathrm{kDa}$, and the $\beta$ subunits, which vary in size from 90-110 kDa, are transmembrane proteins with generally short cytoplasmic domains. The exception is $\beta 4$, which has a 1000-amino-acid-long cytoplasmic tail. The cytoplasmic tails are important in intracellular signaling and, at least for the $\beta$ subunits, are important for interacting with components of the cytoskeleton, such as $\alpha$-actinin and talin (Clark and Brugge, 1995). The specificity of the integrin receptor is due to the particular $\alpha \beta$ 
combination that forms the extracellular globular head. An individual integrin can have several different ligands. For example, $\alpha 4 \beta 1$ [very late antigen (VLA) -4 ] can bind fibronectin (FN), invasin, and vascular cell adhesion molecule-1 (VCAM-1). In addition, a given ligand can be recognized by several different integrins. $F N$ is recognized by $\alpha 3 \beta 1$ (VLA-3), $\alpha 4 \beta 1, \alpha 5 \beta 1$ (VLA-5), $\alpha 4 \beta 7$, and $\alpha \mathrm{v} \beta 3$ (Diamond and Springer, 1994). With the exception of mature erythrocytes, at least one integrin receptor is expressed on all cell types (Diamond and Springer, 1994). Integrin ligands include members of the lgSF |intercellular adhesion molecule (ICAM)-1, ICAM-2, VCAM-1 ], ECM components (see below), and viral and bacterial proteins. Important integrin receptor-ligand pairs in lymphocyte-endothelial interactions include: the LFA1/ICAMs -1 and $-2, \alpha 4 \beta 1 /$ NCAM-1, $\alpha 4 \beta 7 /$ NCAM -1 , and $\alpha 4 \beta 7 /$ MAdCAM -1

Several recently described integrin molecules, pertinent to lymphocyte-endothelial interactions, deserve attention. Until recently, the $\beta 2$ integrin family was made up of three structurally related $\beta 2$-containing heterodimers: LFA-1 (CD1la/CD18), Mac-1 (CD1 lb/CD18), and $\mathrm{p} 150,95$ (CD1/c/CD18). A novel $\beta 2$ integrin, $\alpha \mathrm{d} \beta 2$, has been discovered on the cell surface of canine leukocytes (Danilenko et al. 1995). The 155-kDa $\alpha \mathrm{d}$ chain is expressed as a heterodimer with $\beta 2$ on macrophage subpopulations, and two types of peripheral blood $\mathrm{CD} 8^{+}$ lymphocytes, large granular lymphocytes and small lymphocytes (Danilenko et al., 1995). The amino acid sequence of canine $\alpha \mathrm{d} \beta 2$ bears significant homology to the recently identified human $\alpha \mathrm{d} \beta 2$ integrin obtained by cDNA cloning (cited in Danilenko et al., 1995). The ligands and functions attributable to canine $\alpha \mathrm{d} \beta 2$ await further evaluation, but human $\alpha \mathrm{d} \beta 2$ has been reported to bind preferentially to ICAM-3 over ICAM-1 (cited in Danilenko et al., 1995).

The $\alpha v \beta 3$ integrin, previously known only to bind many ECM proteins and components of the coagulationcascade, has recently been shown to be a ligand for the IgSF member, CD31 (platelet-endothelial cell adhesion molecule (PECAM)-1] (Piali et al., 1995). This is the first heterophilic CD31 ligand to be identified. The $\alpha v \beta 3: C D 31$ interaction is cation-dependent, involves the second Iglike domain of $C D 31$, and can be blocked by anti-CD31 and anti- $\beta v \beta 3$ antibodies (Piali et al., 1995). $\alpha v \beta 3$ is expressed by many different cell types, including ECs, mast cells, natural killer (NK) cells, dendritic epidermal T-cells, and activated T-cells (Piali et al., 1995). The ability of $\alpha v \beta 3-$ and CD31-specific mAbs partially to block the adhesion of lymphokine-activated killer cells to an endothelial cell line suggests that the $\alpha v \beta 3: C D 31$ interaction may play a role in lymphocyte adhesion to endothelium in vivo.

Several other recent discoveries have involved the $\alpha 4$ integrins and their ligands. By protein isolation, amino acid sequence analysis, and peptide blocking, it was shown that $\alpha 4 \beta 1$ and $\alpha 4 \beta 7$ recognize a leucineaspartic acid-valine (LDV) sequence found in the $\alpha 4$ subunit itself (Altevogt $e t$ al., 1995). This result is consistent with earlier findings demonstrating inhibitory or enhancing effects of $\alpha 4$-specific mAbs on cell-cell interactions in lymphoid cell populations that do not express any of the previously identified $\alpha 4$ ligands. In another study, the crystal structure of a $\alpha 4 \beta$ I-binding fragment of the first two domains of the VCAM-1 molecule was determined. This model demonstrated a highly-exposed integrinbinding motif $\left(\mathrm{O}^{38}\right.$ IDSPL) contained within the $\mathrm{N}$-terminal region of the loop between $\beta$-strands $C$ and $D$ in domain 1 of the VCAM-1 molecule (Jones et al., 1995). This binding motif exhibited a unique conformation that the authors predicted will be common to all integrinbinding IgSF motifs. Last, a study looking at the CS-1 region of FN, VCAM-I, and MAdCAM-I binding sites on $\alpha 4 \beta 1$ found that the putative binding sites were all contained within a small region of the $\alpha 4$ chain (residues 107-268) (Kamata et al., 1995).

A great deal of our insight into the regulation and function of the $\beta 2$ integrins has been elucidated by a severe genetic immunodeficiency syndrome, leukocyte adhesion deficiency (LAD), that was first identified in 1979 among six infants with delayed separation of the umbilical cord, recurrent bacterial infections, and abnormal neutrophil function (reviewed in Harlan, 1993). The major clinical manifestations of the LAD syndrome include recurrent bacterial soft tissue infections, chronic gingivoperiodontitis, and impaired wound healing, all in the face of a chronic neutrophilic leukocytosis. The LAD syndrome is now known to be due to various mutations in the 32 subunit gene (Harlan, 1993; Lopez Rodriguez et al., 1993). The LAD phenotype can range from severe, which is associated with death during infancy and $<1 \%$ of the normal cell-surface LFA-1, Mac-1, and p150,95 integrins, to mild, which is associated with fewer infections and survival into adulthood, and up to $30 \%$ of normal cell-surface $\beta 2$ integrin expression (Harlan, 1993). Although neutrophil emigration is profoundly impaired in LAD patients, lymphocyte trafficking is less severely affected. T-lymphocytes from LAD patients demonstrate reduced levels of basal binding to unstimulated endothelium, but demonstrate a normal enhancement of adhesion to TNF- $\alpha$-stimulated endothelium, due to $\alpha 4 \beta 1$-mediated interactions (Vennegoor et al., 1992).

\section{(D) IMMUNOGLOBULIN SUPERFAMILY}

The IgSF encodes a large family of proteins with many different functions, including antigen recognition and cellular adhesion (reviewed in Picker, 1994; Carlos and Harlan, 1994; Hynes, 1994). Members of this family all contain at least one region showing similarity to a com- 
mon, well-preserved ancestral protein domain originally identified in immunoglobulin variable and constant regions. These domains (70-110 amino acids) are arranged in a sandwich of two sheets of anti-parallel $\beta$ strands apposed via hydrophobic faces. These $\beta$ strand loops serve as the specific binding sites for the IgSF counter-receptors. Several members of the IgSF are involved in T-cell-EC interactions, namely, CD31 on Tcells and ICAM-1 (CD54), ICAM-2 (CD 102), VCAM-1 [CD 106], CD31, and MAdCAM-1 on EC.

ICAM- 1 is expressed on EC, thymic and mucosal epithelial cells, mononuclear cells, and fibroblasts. ICAM- 1 has five immunoglobulin-like domains and is recognized by LFA-1 and Mac-1. Similar to E-selectin, ICAM- 1 can be transcriptionally up-regulated by TNFB. IL-1, and LPS, but has a longer time-course of expression (reviewed in Carlos and Harlan, 1994). ICAM-2 has two Ig-like domains and is recognized by LFA-1. ICAM-2, like ICAM- $\mathrm{I}$, is expressed on resting ECs but, unlike ICAM-1, is not up-regulated by inflammatory stimuli (Carlos and Harlan, 1994).

VCAM-1 is not expressed on normal endothelium, but can be transcriptionally up-regulated by the same inflammatory stimuli listed above for E-selectin and ICAM-1. Although the predominant form of VCAM-I on endothelium consists of $7 \mathrm{Ig}$ domains, VCAM-1 forms containing 6 and 8 domains have also been identified (Hession et al., 1991). The 6-domain form is generated through alternative splicing and lacks the fourth domain. In addition, a phosphatidyl inositol (PI)-linked form, containing only the $3 \mathrm{~N}$-terminal lg-like domains, has been identified on inflamed murine tissues (Moy et al., 1993). $\alpha 4 \beta 1$ is capable of interacting with all forms of VCAM-1, including the Pl-linked form, and is known to interact with domains 1 and 4 on the 7-domain form of VCAM-1 (Kilger et al., 1995). $\alpha 4 \beta 7$ binds the 7-domain form of VCAM-1; other forms have not been tested.

Recent additions to the IgSF include ICAM-3, CD31, and MAdCAM-1. Unlike ICAM-1 and ICAM-2, ICAM-3 is not expressed on EC, but is expressed at high levels on T-lymphocytes (De Fougerolles and Springer, 1992; Campanero et al., 1994). ICAM-3 participates in T-cell activation and can regulate the LFA-1/ICAM-1 adhesion pathway (Campanero et al., 1994). CD31 is constitutively expressed on HEV, platelets, neutrophils, monocytes, and on certain T-cell subsets. CD31 is known to mediate cell-cell interactions via a homophilic interaction. Expression of CD31 is primarily localized to intercellular contact points, where CD31-CD31 homophilic binding occurs. As described above, CD31 can also interact with the $\alpha v \beta 3$ integrin. In addition to its role as an adhesion molecule, engagement of the CD31 receptor can transduce intracellular signals that result in up-regulation of $\alpha 4$ integrin activity (Tanaka et al., 1992). MAdCAM-1 is expressed primarily on Peyer's patch HEV, mesenteric LN
$\mathrm{HEV}$, and mucosal lamina propria venules and is the only IgSF member known to date to have both mucin-like and IgSF-like characteristics.

\section{(E) Cadherins}

The cadherins are a family of calcium-dependent transmembrane cell adhesion proteins that bind primarily through homophilic and heterophilic interactions (reviewed in Shapiro et al., 1995; Patel and Gumbiner, 1995). Cadherins are known to be important in embryonic development and maintenance of tissue architecture via cell-cell junctions, including desmosomes and zonula adherens. New evidence suggests a possible role for cadherins in lymphocyte localization and immune surveillance (Cepek et al., 1994). All cadherins cloned to date have a similar primary structure. These proteins are 723 748 amino acids long, with a putative signal peptide sequence, an extracellular portion containing 3-5 tandem repeat domains, a hydrophobic transmembrane anchor, and a long cytoplasmic tail.

There are currently four subclasses of cadherins: (1) the E-cadherins (uvomorulin, cell CAM 120/80, Arc-1 or L-CAM), which are expressed on adult epithelial cells; (2) the $\mathrm{N}$-cadherins (A-CAM, N-Cal-CAM), which are expressed on adult neural tissue, the lens of the eye, and muscle; (3) the P-cadherins, which are transiently expressed in several tissues during development as well as in the placenta and epithelium in adults; and (4) the $\mathrm{R}$-cadherins. Studies using $\mathrm{N}$-cadherin have demonstrated that both the extracellular domain and the cytoplasmic tail, which interacts with the cytoskeleton and intracellular proteins called catenins, must be intact for adhesion to occur. Binding specificity of the cadherins is contained within the first $\mathrm{N}$-terminal domain (Patel and Gumbiner, 1995). X-ray crystallography of the $\mathrm{N}$-terminal domain of murine $\mathrm{N}$-cadherin (NCD1) revealed a twodimer interface that combines to form a zipper-like structure (Shapiro et al., 1995). It was suggested that this interdigitating zipper-like "supermolecular ribbon" is the basic unit of cadherin adhesive function. To date, cadherins have not been reported to be expressed on endothelial tissue. However, intra-epithelial lymphocytes (IEL) have been found to bind to intestinal epithelial cells via the interaction of the $\alpha E \beta 7$ integrin and $E$ cadherin on epithelial cells (Cepek $e$ t al., 1994). Thus, it is possible that cadherins may play a yet-undiscovered role in lymphocyte-endothelial interactions.

\section{(F) OTHER ADHESION MOLECULES}

Cell adhesion molecules that currently do not fit into the adhesion families discussed above include CD44, VAP-1, and LVAP-2. CD44, which mediates adhesion to hyaluronic acid (HA), is a widely distributed, highly glycosylated integral membrane protein composed of many different isoforms, with molecular weights ranging from 

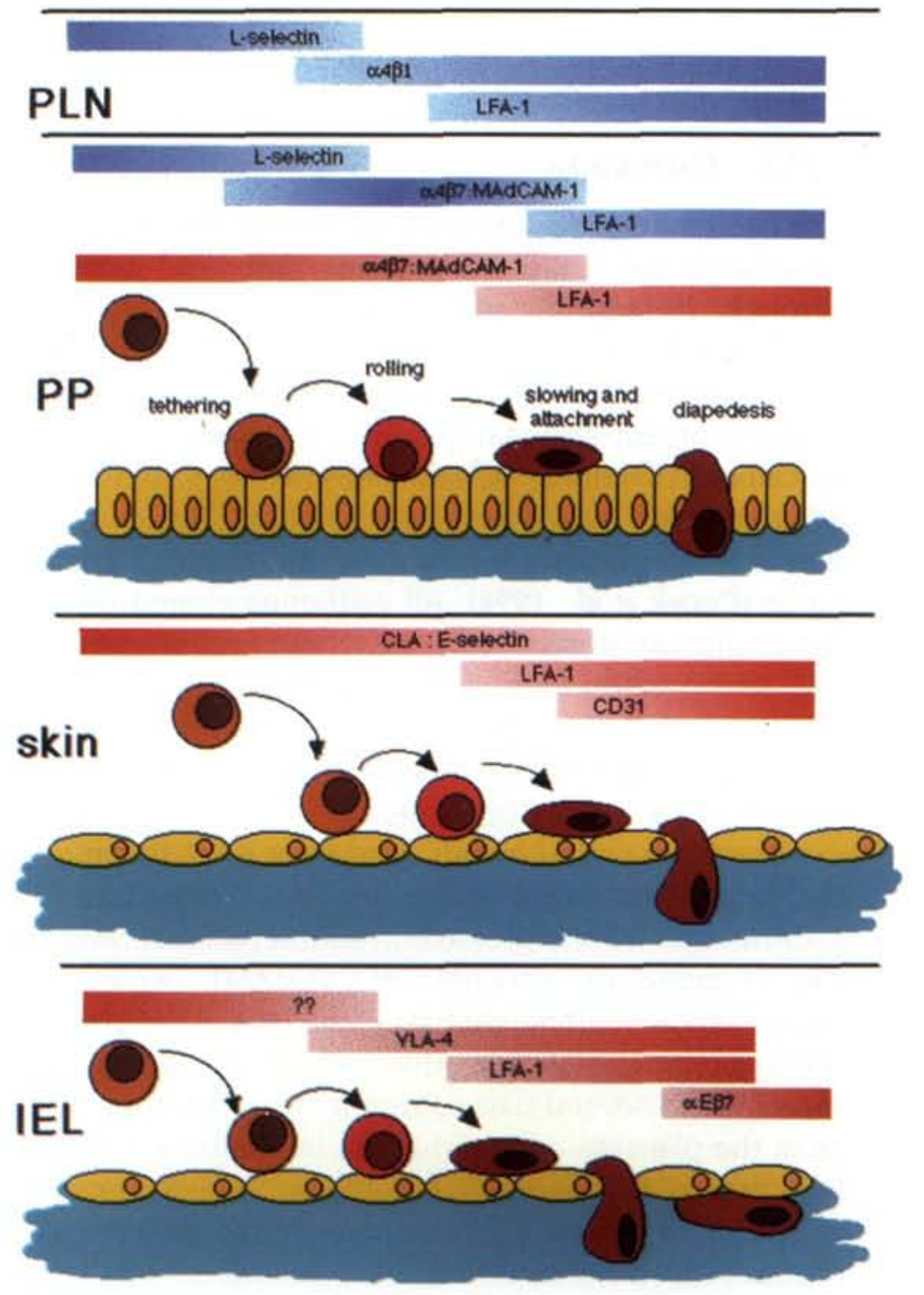

Figure 2. The adhesion cascade. The multistep process of T-cell interaction with endothelium is shown for both naive (blue) and memory (red) T-cells, including the relevant adhesion molecules. Rolling, attachment, and diapedesis of T-cells through HEV in peripheral lymph nodes (PLN), and Peyer's patches (PP) (top), through endothelium in skin (middle), and of intra-epithelial lymphocytes (IEL) to endothelium in the gut (bottom) are illustrated. The color intensity of the T-cells is intended to illustrate relative states of activation. Light blue, underlying basement membrane/tissue. See text for further details.

85-160 kDa (Lesley et al., 1993). Lymphocytes express the standard $90-\mathrm{kDa}$ form of CD44 at rest and different variable forms with activation (Koopman et al., 1993).

CD44 has been implicated in lymphocyte recirculation, adhesion, and activation. However, the role of the CD44 molecule in these processes is ill-defined. CD44 participates in lymphocyte binding to hyaluronidasesensitive components on activated ECs. Polyclonal antiserum to CD44 can inhibit lymphocyte binding to HEV. An anti-CD44 mAb, Hermes-3, can block lymphocyte binding to mucosal HEV in a Stamper-Woodruff frozensection assay, but does not appear to work through the HA pathway, suggesting that this antibody does not block lymphocyte binding to HA. This antibody also shows a potent inhibition of T-cell proliferation in response to phytohemagglutinin, suggesting that Hermes-3 blocks or induces unique signaling events mediated through CD44. Picker et al. (1989) showed that leukocyte CD44 and mesenteric LN-derived MAdCAM-1 could interact in solution in a specific, saturable, and reversible manner. However, the Hermes-3 mAb was unable to inhibit lymphocyte binding to purified MAdCAM-1 on Peyer's patch HEV. Lymphocytes that have shed their CD44 are unable to generate the early phase of an anti-hapten delayed-type hypersensitivity (DTH) response, but no effect on lymphocyte recirculation was observed (Camp et al., 1993). Lymphocytes strongly express soluble CD44 (lacking exons 5-14), a 90$\mathrm{kDa}$, heavily glycosylated secreted protein. Stimulation of T-cells with anti-CD3 mAb, phorbol myristate acetate (PMA), or specific antigen leads to expression of a variety of splice variants, especially those expressing the v6 exon. This exon is also contained in some highly aggressive non-Hodgkin lymphomas. Since activated lymphocytes and lymphomas express v6 variants, they may have similar infiltrative, adhesive, and migratory properties.

Vascular adhesion protein-1 (VAP-1), first identified by use of the mAb $1 B 2$ (made by immunizing mice with human synovium), is a $90-\mathrm{kDa}$ endothelial adhesion protein expressed primarily on HEV and HEV-like venules in PLN, synovium, and tonsils (Jalkanen and Salmi, 1993; Carlos and Harlan, 1994). VAP-1 is not expressed on large-vessel endothelium or human umbilical vein endothelial cells (HUVEC) (McEver, 1994). VAP-1 localization to the lumenal surface of the endothelium, and its granular cytoplasmic staining, suggest that VAP-1 is stored in granules (Jalkanen and Salmi, 1993). VAP-1 is a promising candidate for the proposed synovial vascular addressin. Lymphocyte-vascular adhesion protein-2 (LVAP-2) is a 70-kDa protein expressed on HUVEC, lymphoid and non-lymphoid venules, B-cells, and CD8 ${ }^{+} \mathrm{T}$ cells (McEver, 1994). LVAP-2 is a putative endothelial adhesion molecule for lymphocytes (McEver, 1994). Recent studies have identified LVAP-2 as CD73 (ecto-5'nucleotidase), a glycosyl phosphatidylinositol-linked molecule that has been previously shown to mediate signals that facilitate T-cell proliferation (Airas et al., 1995).

\section{(III) The Adhesion Cascade}

The cascade of events that enables lymphocytes to emigrate from the blood into the surrounding tissue is a normal part of T-cell trafficking and is also required in the Tcell response to tissue damage and disease. This process of diapedesis and extravasation is dependent on the expression of specific adhesion and signaling molecules in both the T-cell and the EC. Specific cell-surface receptors, including members of the selectin, integrin, IgSF, and serpentine (7-transmembrane, G protein-coupled) families, are involved in each step of this process. In 
addition, successful diapedesis requires the appropriate temporal expression of signaling molecules involved in the activation of both the T-cell and EC.

The adhesion molecules involved in adhesion and diapedesis have been most thoroughly characterized for neutrophil-EC interactions. However, recent data suggest that the same types of interactions, using the same classes of adhesion molecules, are also used by lymphocytes for diapedesis. Previous studies have indicated that there are, in general, four steps in the adhesion cascade: (1) tethering and rolling, (2) activation, (3) stable adherence, and (4) extravasation (Fig. 2). Since recent evidence suggests that different adhesion molecules may be involved in the stabilization of adherence and subsequent extravasation of lymphocytes, these steps will be considered separately. The first step of the process, tethering and rolling, is mediated by interaction of members of the selectin family on both the T-cell and EC and their carbohydrate ligands. This rolling step, which is reversible, permits the lymphocyte to search regions of the vessel wall for the presence of appropriate chemical mediators, or chemokines, that mark sites of inflammation and disease. interaction of the chemokine with its receptor on the T-cell results, through a G-protein-coupled mechanism, in the activation of integrin molecules on the T-cell (step 2). At the same time, other inflammatory mediators (TNF- $\alpha, \quad[\mathrm{L}-1 \beta)$ up-regulate or activate specific cell-adhesion molecules on the EC. Activation of specific integrin molecules on the T-cell results in increased binding of the receptor to its ligand, a member of the IgSF, on the EC. This interaction results in the stable arrest and firm attachment of the T-cell to the EC (step 3). Finally, another integrin:IgSF pair is responsible for the transmigration of the lymphocyte through the vessel wall (step 4). Each of these steps will be described in detail below

\section{(A) Step 1: Tethering and Rolling}

The initial phase of the adhesion cascade is mediated, in both lymphocytes and neutrophils, to a large extent by the selectins. However, recent evidence suggests that integrin: IgSF interactions may also play a role in this process in some cell populations (see below).

$\mathrm{L}$-selectin is the major T-cell adhesion molecule involved in tethering and rolling. L-selectin binds to peripheral node addressin (PNAd), a mixture of glycoproteins expressed on PLN HEV. These mucin-like ligands. GlyCAM-1 and CD34, contain an epitope recognized by the MECA-79 antibody (Streeter et al., 1988). Sulfation is required for binding of L-selectin to GlyCAMI and CD34 (Imai et al., 1993). L-selectin also binds to MAdCAM-1, which is present on mucosal HEV, but not PLN HEV (Berg et al., 1993).

Numerous in vitro studies support a role for Lselectin in T-cell tethering and rolling on EC.
Lymphocytes, neutrophils, and monocytes will bind to cytokine-activated EC in a Stamper-Woodruff assay, and mAbs to L-selectin are able to reduce this binding (Smith et al., 1991; Spertini et al., 199 l b; Brady et al., 1992). Moreover, L-selectin can mediate the attachment of Tlymphocytes under flow to purified MAdCAM-1 coated on a glass plate (Berg et al., 1993). In addition, Lawrence et al. (1995) recently showed that PNAd supports lymphocyte and neutrophil tethering and rolling under shear stress. Finally, cells transfected with L-selectin CDNA can induce rolling in the absence of both $\mathrm{E}$ - and P-selectin (Ley et al., 1993).

More recent studies have focused on the role of Lselectin in tethering and rolling by means of in vivo systems. Mice made deficient in L-selectin expression show a reduction in the number of leukocytes found in PLN. and a reduced number of lymphocytes in lymphatic tissue (Arbones et al., 1994). In these mice, lymphocytes were unable to attach to PLN HEV in in vitro binding assays. However, PLN still contained about $30 \%$ of the normal number of lymphocytes in this tissue, indicating that some lymphocytes can enter PLN through an Lselectin-independent mechanism. These data suggest that other adhesion molecules may be involved in tethering and rolling. This same study showed that there was a $70 \%$ decrease in the number of rolling cells, as determined by intravital microscopy, suggesting that Lselectin is involved in the initial stages of the adhesion cascade.

Although L-selectin is a major player in the initiation of the adhesion cascade in T-cells, there is clear evidence that other adhesion molecules are also involved in this process. Many memory T-cells are L-selectin-negative, and thus, must tether and roll using other adhesion molecules. In vitro studies using parallel-plate flow chambers have shown that L-cells transfected with E-selectin will support primary adherence of T-cells (Jones et al., 1994), whereas ICAM-1 transfectants could mediate only stable adherence. When HUVECs were used in the same assay, there was a significant amount of heterogeneity in the adherent behavior of peripheral blood T-cells under flow. This may be the result of the functionally and phenotypically distinct populations of T-cells present in peripheral blood. The authors were unable to identify a mAb that could block primary adherence, thus excluding a role for L-selectin, VCAM-1, $\alpha 4 \beta 1, \alpha 4 \beta 7$. MAdCAM-1, and CD44 in this system. In addition, Lawrence et al. (1995) showed that E-selectin can mediate T-cell tethering and rolling under shear flow conditions. Studies with the L-selectindeficient mice also indicate that other adhesion molecules are involved in primary adherence (Arbones et al. 1994). While there was a significant decrease in the number of cells entering the PLN, this effect was reduced in mesenteric LN, suggesting that expression of MAdCAM1 in this tissue may mediate primary adherence of $\alpha 4 \beta 7^{+}$ 
T-cells. The integrins $\alpha 4 \beta 1$ and $\alpha 4 \beta 7$ may be uniquely adapted to play roles in both primary (tethering and rolling) and secondary (stable arrest) adhesion steps.

Indeed, several recent studies clearly show that $\alpha 4$ integrins may play a role in initial tethering and rolling. As mentioned above, Jones et al. (1994) showed that while E-selectin- and ICAM-1-transfected L-cells could mediate only primary and secondary T-cell adherence, respectively, VCAM-1 transfectants could mediate both. In another study, Berlin et al. (1993) showed that $\alpha 4 \beta 7$ could support rapid binding and rolling of cells to recombinant MAdCAM-1 under shear flow in vitro, and that this binding was independent of selectins. In addition, activated lymphocytes were shown to bind and roll on venules in the lamina propria of the small intestine, in situ, through an $\alpha 4 \beta 7$ :MAdCAM -1 interaction. Antibodies to $\alpha 4$ or MAdCAM-1 completely blocked these interactions, whereas anti-E-selectin or anti-LFA-1 antibodies had no effect. Recombinant VCAM-1 was also capable of supporting primary adhesion of resting or activated LN cells in a selectin-independent manner. Finally, cells expressing either $\alpha 41$ or $\alpha 4 \beta 7$ bound VCAM1 under flow.

During initial attachment, T-cells flowing through the vessel must be capable of attaching to ligands on the EC wall in a fraction of a second. Slow rolling of the lymphocyte on the cell wall allows the T-cell to inspect the area for the presence of appropriate chemical mediators. Electron microscopy studies have shown that L-selectin is expressed at the tips of microvilli on lymphocytes (Picker et al., 1991). This part of the cell would be the first to come into contact with the cell wall. Concentration of L-selectin in microvilli may increase the avidity of the interaction of L-selectin with its ligand. This localization may also position L-selectin above the glycocalyx and allow for more rapid interaction with ligand. Lawrence and Springer (1991) hypothesized that, to facilitate rolling, there must be a continual series of breaking and formation of interactions between the selectins and their ligands. The prediction that selectins have rapid association and dissociation rate constants has been supported by recent studies (Ushiyama et al, 1993; Alon et al., 1995; Lawrence et al., 1995). These studies showed that lymphocytes attach to and roll on PNAd, associating and dissociating quite easily. However, on average, the T-cells were tethered greater than $95 \%$ of the time. Several studies have suggested that $\mathrm{L}$-selectin function is dependent on an affinity change in the molecule (Spertini et al., 1991a), and that this activation requires the L-selectin cytoplasmic domain (Kansas et al., 1993).

While it is clear that expression of L-selectin facilitates lymphocyte trafficking through interaction with its EC ligand, the lack of L-selectin expression on other Tcells may also play a role in overall trafficking. While there was a decrease in the number of lymphocytes in
PLN of L-selectin-negative mice, there was a similar increase in the number of cells found in Peyer's patches and spleen (Arbones et al., 1994). These data suggest that because the lymphocytes did not traffic to the PLN HEV, there was a greater probability that cells would traffic to other tissues. It has been suggested that soluble Lselectin, as well as soluble ligands for L-selectin (i.e., soluble GlyCAM-1), may play a role in T-cell trafficking (Brustein et al., 1992; Schleiffenbaum et al., 1992). The potential role of these molecules in T-cell trafficking will be discussed below.

\section{(B) Step 2: Activation}

The second phase of the adhesion and transmigration process involves activation of T-cell adhesiveness, primarily through signaling molecules called chemokines. In addition to inducing increased adhesion, these peptide chemoattractants serve to direct the T-cell to the site of tissue destruction or disease. Chemokines are small (70-100 amino acid) peptides expressed by a variety of cell types, including T-cells, monocytes, eosinophils, basophils, mast cells, EC, smooth muscle cells, fibroblasts, keratinocytes, and chondrocytes (Springer, 1994). Chemokines fall into two distinct classes, the $\alpha(C-X-C)$ and $\beta(C-C)$ chemokines, based on sequence similarity and the amino acid sequence around the first two cysteine residues in the molecule. The $\alpha$ chemokines act primarily on neutrophils; IL-8 is the prototype chemokine of this family. The $\beta$ chemokines act primarily on monocytes, lymphocytes, and eosinophils, and include monocyte chemoattractant proteins 1,2 , and 3 (MCP-1, 2, 3). macrophage-inhibitory protein- $\alpha$ and $\beta$ (MIP- $1 \alpha$ and $\beta$ ). RANTES (regulated on activation normal $T$ expressed and secreted), and eotaxin. In a recent study, MCP-1 was shown to be a major chemoattractant for peripheral blood T-cells (Carr et al., 1994).

Chemokines are found at sites of inflammation and disease and help direct appropriate effector cells to these sites. In response to the chemokine, leukocytes travel in the direction of increasing concentrations of the chemoattractant, being able to detect a $1 \%$ concentration gradient across the diameter of the cell. T-cells come into contact with chemokines while rolling on the vessel wall. The precise mechanism by which T-cells come into contact with chemokines is not clear. One possibility is that chemokines are simply released into the blood vessel and T-cells are able to bind as a result of the higher local concentration in that area. Alternatively, there is evidence that chemokines may be presented to T-cells by proteoglycans in the ECM (Gilat et al., 1994), cell-surface proteoglycans, such as CD44 (Tanaka et al., 1993a), or promiscuous chemokine receptors, such as the Duffy blood group antigen (Horuk et al., 1994). Heparin binding sites on the chemokines may provide a site for interaction with proteoglycans. Chemokine presentation may 
permit an additional layer of diversity and specificity to develop in the adhesion cascade.

Chemokines bind to cells through specific serpentine (seven-transmembrane), G-coupled protein receptors. Engagement of the receptor by the chemokine leads to a rapid (1-3 seconds) activation of the cell-surface integrin molecules, $\alpha 4 \beta 1, \alpha 4 \beta 7$, and LFA-1. This increased adhesion is accomplished without an increase in the number of adhesion molecules on the cell surface (see below). Coupling of the chemokine receptor to $G$ proteins (usually $G \alpha_{i}$ ) is essential. Treatment of cells with pertussis toxin, a specific inhibitor of $G \alpha_{i}$, leads to an exclusive rolling phenotype (Bargatze and Butcher, 1993), in which rolling is prolonged and there is a complete block of stable arrest in treated cells.

Although chemokines have been proposed to be the major activating stimulus in the adhesion cascade, the ability of receptor-ligand interactions to transduce signals that up-regulate integrin activity must also be considered in the context of the adhesion cascade model. Engagement of $C D 31$ by soluble bivalent mAb has been reported to be sufficient to up-regulate $\beta 1$ integrin activity on CD31-expressing T-cells (Tanaka et al., 1992). These studies suggest that engagement of CD31 on T-cells, perhaps via $C D 31$ or the $\alpha v \beta 3$ integrin on endothelium, may play a role in activating integrin receptors expressed on $\mathrm{T}$-cells that are weakly tethered to the endothelial surface Other candidate triggering receptors on T-cells are selectins and selectin ligands, since recent findings demonstrate that L-selectin engagement or the interaction of neutrophils with E-selectin results in increased functional activity of $\beta 2$ integrins (Lo et al., 1991; Simon et al. 1995) In addition, the $\alpha 4$ subunit itself has recently been identified as a ligand for $\alpha 4 \beta 7$ and $\alpha 4 \beta 1$ (Altevogt et al. 1995) This interaction may represent a novel mechanism for autologous integrin activation through homotypic aggregation. The physiologic relevance of this interaction is unknown. Finally, Jones et al. (1994) have shown that T-cells will bind and stably adhere (a step thought to require integrin activation) to L-cells expressing VCAM1 . This result suggests a role for $\alpha 4 \beta 1$ engagement in integrin activation. These studies propose an intriguing hypothesis that the molecule(s) mediating initial tethering and rolling may also serve as the stimulus that eventually results in stable arrest.

\section{(C) Step 3: Stable arRest}

Activation of the T-cell by chemokines leads to the third step in the adhesion cascade, stable arrest or firm attachment to the endothelium. This event is mediated by activated integrins on the surface of the T-cell $(\alpha 4 \beta 1$, $\alpha 4 \beta 7$. LFA- 1 ) and IgSF adhesion molecules (VCAM- 1 and ICAM-1) on the EC. As mentioned above, the increase in adhesiveness is accomplished without an increase in the number of integrin molecules on the surface of the T-cell.
This triggering of a high-avidity state is important in the transition of binding from primary (tethering and rolling) to secondary (stable arrest) adhesion (Jones et al., 1994).

Several receptor-ligand interactions may be involved in stable arrest of T-cells to the vessel wall. Only members of the $\beta 1, \beta 2, \beta 3$, and $\beta 7$ integrin family are expressed on T-cells, the key players for EC adhesion being $\alpha 4 \beta 1, \alpha 4 \beta 7$, and LFA-1. LFA- 1 binds to ICAM- 1 and ICAM-2, both of which are expressed on HEV (Marlin and Springer, 1987; Staunton et al., 1989). Inflammatory mediators, such as TNF- $\alpha$ and IL- I, strongly increase ICAM-1 expression on EC (Dustin et al., 1986; Pober et al, 1986). ICAM-2 expression is high on unstimulated EC cells and is not increased by inflammatory mediators (Staunton $e t$ al, 1989). VCAM-1, the ligand for $\alpha 4 \beta 1$, is expressed on endothelium activated by inflammatory mediators such as TNF, IL-1 $\beta$, IL-4, and interferon (IFN)- $\alpha$ (Osborn et al., 1989). In addition, VCAM-1 is expressed in other lymphoid areas (LN, tonsils, intestinal lymphoid tissues). macrophages on the splenic red pulp and fetal thymus, hepatic Kupffer cells, and synovial lining layer cells in the synovium of patients with rheumatoid arthritis.

Stable arrest of T-cells to EC is activation-dependent. Using an in vitro flow chamber, Lawrence and Springer (1991) showed that resting T-cells bind to PNAd. but bind to ICAM- 1 only following activation. Thus, a second signal is required to activate $\beta 2$ integrin-dependent binding. Jurkat cells rolling on PNAd could be induced to arrest stably on ICAM-1 following stimulation with PMA. Increased adhesiveness to ICAM-1 occurs in a timeframe of seconds. Jones et al. (1994), using a parallelplate flow chamber, showed that L-cell transfectants expressing VCAM-1 could mediate primary and secondary adherence of T-cells under flow. However, L-cells expressing ICAM- 1 could mediate only secondary adherence. This difference in primary adherence between $\alpha 4 \beta 1$ and LFA-I was not due to the activation state of these molecules, since there was no difference in primary adhesion of PMA-treated T-cells on L-cells expressing either VCAM-1 or ICAM-1. This difference is likely due to differences in the structures of these molecules or to the physical properties of the interactions. Recent data suggest that both $\alpha 4 \beta 1$ :VCAM-1 and LFA-1:ICAM-1 interactions may play a role in stable arrest of T-cells to EC (Jones et al., 1994). No reduction in adherence is observed if either pathway is blocked by mAbs, but there is complete arrest if both pathways are blocked. Either pathway seems to be capable of providing a sufficient number of receptors for stable adhesion. It appears that both sets of integrins may contribute to slowing of cells that roll, but not enough to achieve stable arrest. PMA significantly increases the fraction of cells that adhere stably, confirming the need for integrin activation. Taken together, these data suggest that, initially, integrins are in a low-avidity state, and that for those cells that adhere 
stably, there is a transition to a high-avidity state involving one or both of the integrins.

Activation of integrins is accomplished through inside-out signaling (reviewed in Hynes, 1992; Mobley et al., 1993). This process is thought to involve conformational changes that lead to a higher affinity of the integrin for ligand. Lollo et al. (1993) have recently shown an increase of approximately 200 -fold in the affinity of a subpopulation of LFA-1 molecules following activation. Additional evidence also supports the hypothesis of actvation-induced conformational changes in integrin receptors. First, mabs have been described that recognize integrins only in their activated state. Second, binding of divalent cations $\left(\mathrm{Mg}^{++}, \mathrm{Ca}^{++}, \mathrm{Mn}^{++}\right)$leads to increased adhesion and a conformational change, as detected by increased binding to conformation-specific mAbs. Finally, some integrin-specific mAbs have been developed that enhance, as opposed to block, adhesion, again suggesting that they induce a conformational change. In addition to increased affinity, integrin-mediated adhesion can be enhanced by stimuli that act on events occurring after receptor occupancy, such as clustering of integrin receptors. One recent study did, in fact. demonstrate that while both an activating $\beta 1$-specific $\mathrm{mAb}$ and PMA treatment resulted in increased adhesion of lymphoid cell lines to $\mathrm{FN}$, only the activating $\beta 1 \mathrm{mAb}$ caused increased affinity of the FN receptor/ligand interaction (Faull et al., 1994).

The intracellular signaling pathways and mechanisms used in integrin activation are not well understood. PMA induction suggests an involvement of protein kinase $\mathrm{C}$. In addition, elevation of intracellular $\mathrm{Ca}^{++}$ or cyclic AMP activates LFA-1. Cross-linking of a variety of T-cell surface antigens (CD3/T-cell receptor, CD28, $\mathrm{CD} 2, \mathrm{CD} 31, \mathrm{CD} 7, \mathrm{CD} 44)$ also leads to activation of integrins (Mobley et al., 1993). Depending on the surface receptors triggered, different signal transduction pathways seem to be involved. The activation of integrins is transient, which allows for de-adhesion, a process that is likely to be as important, and as complex, as adhesion. In addition, $\mathrm{T}$-cell binding of ligand, i.e., $\alpha 4 \beta 1$ :VCAM-1, can cause outside-in signaling. This process may be important for subsequent steps in the adhesion cascade, as well as for other important processes such as proliferation and differentiation (Shimizu and Shaw, 1991; Pardi et al., 1992).

\section{(D) Step 4: Diapedesis}

The mechanisms involved in diapedesis remain poorly characterized. It is clear that integrin:IgSF interactions are involved in leukocyte diapedesis, since mAbs to $\beta 2$ integrins could completely abrogate stable adherence and diapedesis (Lawrence and Springer, 1991). The identity and the extent of integrin:IgSF involvement in lymphocyte diapedesis are unknown. It is also thought that diapedesis toward a region of tissue damage is unidirectional. Thus, chemokines are likely candidates to direct this process by providing the gradient for lymphocytes to follow. It is possible that the chemokines involved in activation are used for establishing the chemotactic gradient. Alternatively, it is possible that other chemokines, soluble factors, or tethered cytokines are involved in this process.

\section{(E) SUMmary}

The various constellations of adhesion and signaling molecules expressed by the lymphocyte and EC determine the types of cells that will eventually migrate into the tissue (see below). To a large extent, it is the adhesion molecules that are expressed on a cell that determine whether it will emigrate or not. While it is clear that certain cell-adhesion molecule interactions are dominant in the various steps of the adhesion cascade, there is compelling evidence for overlap in their functions (Fig. 2). In addition, it appears that levels of expression are paramount in the involvement of a particular molecule in any given step. As suggested by Butcher (1993), the differences in expression of these molecules may be quantitative rather than qualitative; it is not whether a cell expresses an adhesion molecule, but the level of expression. If a four-step adhesion cascade is assumed, a cell that shows even a two-fold increase in efficiency at each step will be 16 times more likely to extravasate successfully. Expression of different combinations of adhesion molecules on distinct subclasses of lymphocytes, and on $E C$ in diverse locations, as well as the ability to respond to only certain activation stimuli, allow for extraordinary diversity and specificity in the adhesion cascade.

\section{(IV) Recirculation Patterns of Peripheral T-cell Subsets}

Peripheral T-cells that have not encountered antigen are considered naïve and can be distinguished by several criteria from memory T-cells, which have undergone antigen-specific activation. The latter set of T-cells can be further divided at least temporally, but also in some phenotypic and functional terms, into recently activated effector cells, and true memory cells that persist after antigenic stimulation.

The expression of distinct surface markers such as CD45 provides a means of differentiating these T-cell subsets. Hence, naïve T-cells express the CD45RA isoform, while memory cells are thought to express the CD45RO isoform (Cerottini and MacDonald, 1989). This conclusion is based on numerous observations (reviewed in Mackay, 1994): (1) T-cell stimulation results in the down-regulation of CD45RA mRNA and up-regulation of CD45RO mRNA; (2) CD45RA expression on the cell surface disappears two to three days after T-cell stimulation, while CD45RO surface expression increases 
after one to two days; (3) the frequency of $\mathrm{CD} 45 \mathrm{RO}^{+}$cells is low in cord blood but is greatly increased in adult peripheral blood (Kern et al., 1994); and (4) there is an age-dependent increase in the percentage of $\mathrm{CD} 45 \mathrm{RO}^{+} \mathrm{T}$ cells in peripheral blood. Although generally useful in distinguishing naïve from memory cells, the conversion from a CD45RA ${ }^{\text {hi }} C D 45 R \mathrm{R}^{-}$to a CD45RA ${ }^{\text {lo }} \mathrm{CD} 45 \mathrm{RO}^{\text {hi }}$ phenotype may not necessarily be unidirectional (Bell and Sparshott, 1990; Fujii et al., 1992), nor may it be applicable to CD8 ${ }^{+}$T-cells (Mobley et al., 1994). Indeed, unlike CD4 ${ }^{+} \mathrm{T}$-cells, in CD8 ${ }^{+} \mathrm{T}$-cells the expression of CD45RA or CD45RO does not appear to correlate with the respective naïve and memory phenotypes (Adamthwaite and Cooley, 1994).

Characteristic expression patterns for adhesion molecules, such as selectins and integrins, can also be used to determine the activation state of T-cells, albeit with some exceptions that will be addressed below. These expression patterns reflect the important role adhesion molecules play in dictating the distinct routes by which naïve and memory T-cells traffic. Tight control of T-cell recirculation routes via specific interactions between $\mathrm{T}$ cell adhesion molecules and their ligands ensures maximal priming of naïve cells and efficient tissue surveillance by memory cells.

Adhesion molecules, such as $\alpha 4 \beta 1$, LFA-1, and ICAM- 1 , are important for binding of T-cells to endothelium and subsequent extravasation. Concordant with naïve to memory T-cell conversion, these adhesion molecules are up-regulated (reviewed in Mobley et al., 1993). Up-regulation of integrin activity occurs in two ways. First, as described above, integrins show an increased affinity/avidity for their respective ligands upon T-cell activation. Second, activated T-cells up-regulate the expression of integrin genes. While in $\mathrm{CD}^{+}$cells the expression of $\beta 1, \beta 5, L F A-1, C D 44$, and CD2 is co-regulated with the expression of $\mathrm{CD} 45 \mathrm{RO}, \mathrm{CD} 8^{+}$memory $\mathrm{T}$ cells are much more heterogeneous, insofar as a subset of $C D 45 R^{+} C D 45 R 0^{-} C D 8^{+}$cells expresses high levels of LFA- 1 , and the CD8 $8^{+}$LFA- $1^{\text {hi }}$ population exhibits bimodal 35 expression (Kern et al., 1994). The ability to bind to and migrate through endothelium correlates with high expression levels of LFA- 1 and $\beta 1$ integrins such as $\alpha 4 \beta 1$ (Pietschmann et al., 1992; Brezinschek et al., 1995), and is thus closely associated with memory rather than naïve Tcells. Treatment of T-cells with phorbol ester activates these molecules, allowing for less-differentiated cells to migrate through endothelium (Pietschmann et al., 1992).

\section{(A) The ROLE OF ADHESION MOLECULES IN NAÏVE T-CELL PRIMING}

Naïve T-cells encounter antigen in the peri-arteriolar sheath of the spleen and the paracortex of LN, and are trapped there by interdigitating dendritic cells (IDC). which present antigen (reviewed in Steinman, 1991; Sprent, 1994). A limited set of adhesion molecules appears to play a role in naĩve T-cell-IDC clustering. Dendritic cells express high levels of LFA-1, ICAM-1, LFA3, and $\beta 1$ integrins (reviewed in Steinman, 1991). LFA$1 /$ ICAM-1 interactions may figure prominently in T-cell interactions with IDC and B cells (reviewed in Metlay et al., 1989). Antibodies to LFA-1 inhibit only B-cell and not IDC clustering with T-cells. These data suggest that superior T-cell clustering with IDC compared with B-cells may be due not only to slightly lower levels of LFA-1 and ICAM-1 on B cells (Cassell and Schwartz, 1994), but also perhaps to (an) additional clustering factor(s) on IDC (Metlay et al. . 1989).

\section{(B) Distinct RECIRCULATION ROUTES}

Although both naĩve and memory T-cells circulate throughout the body, they utilize distinct routes as a consequence of the differential expression of a number of adhesion molecules (reviewed in Springer, 1994) (see Fig. 2). Naïve cells migrate homogeneously and virtually exclusively to secondary lymphoid tissues such as PLN, Peyer's patches, tonsils, and spleen, but rarely to extralymphoid tissues (Picker, 1994). In contrast, memory cells home to both lymphoid and nonlymphoid tissues (Mackay, 1992).

Naîve T-cells circulating in the blood enter LN by extravasation through HEV, which are characterized by a lining of tall endothelial cells arising from cytokineinduced differentiation of flat endothelial cells. These cells leave LN via the efferent lymphatic vessels, move into the thoracic duct, and then back into the blood. Memory T-cells reside primarily in tissues, entering through non-HEV postcapillary venules. These T-cells enter LN via afferent lymphatic vessels but exit by the same route as naïve T-cells. Emigration to the spleen has been less well characterized, but does not involve HEV (reviewed in Springer, 1994).

\section{(C) Peripheral LYMPH NOde homing AND L-SELECTIN}

Movement of naïve T-cells through PLN HEV involves tethering via selectins, followed by tight integrin-mediated binding. LFA-1/ICAM-1 interactions appear to be important in this latter step, since a mAb specific for LFA-1 can reduce or even abolish T-cell migration into PLN (Camp et al., 1993). P-selectin appears to precede Lselectin in mediating initial contact of T-cells with vascular endothelium, at least in the case of resting $\mathrm{CD} 4^{+}$cells rolling on TNF- $\beta$-activated HUVEC (Luscinskas et al., 1995). The relevance of P-selectin in T-cell rolling on HEV in a non-inflammatory milieu is not clear. On the other hand, the importance of L-selectin for rolling has been clearly demonstrated. L-selectin is expressed on the surfaces of all naïve T-cells and thus is instrumental in 
directing these cells to PLN. An important exception has been demonstrated in fetal lambs, in which only about half of all naïve thymic emigrants are L-selectin ${ }^{+}$ (Witherden et al., 1994). Subsequent L-selectin up-regulation by naïve cells appears to be an antigen-independent component of extrathymic maturation. A large number of mature, naïve ovine $\mathrm{CD} 8^{+} \mathrm{T}$-cells remain $\mathrm{L}$ selectin, which correlates with their reduced presence in LN compared with $\mathrm{CD} 4^{+}$cells (Young et al., 1993). The importance of L-selectin in T-cell trafficking via $\mathrm{HEV}$ has already been discussed earlier in this review.

Upon T-cell activation, L-selectin is selectively down-regulated: In humans, activated T-cells express Lselectin in a tissue-dependent manner (Picker et al. 1993a). T-cells associated with mucosal lymphoid tissue (e.g., tonsils) down-regulate L-selectin, while T-cells associated with PLN remain L-selectin ${ }^{+}$. Subsequently, the L-selectin phenotype of memory T-cells is bimodal. L-selectin is also rapidly shed from the cell surface following activation. It has been suggested that this may represent a mechanism by which lymphocyte trafficking could be modulated, rapidly leading to accumulation of cells in the appropriate tissue. Loss of L-selectin via shedding may also be a prerequisite for subsequent diapedesis. Similarly, Tedder et al. (1995) speculate that Lselectin, shed from activated leukocytes, may play a role as a "buffer" to prevent leukocyte attachment to sites of subacute inflammation.

Compared with $\mathrm{CD} 4^{+}$T-cells, L-selectin expression by $\mathrm{CD} 8^{+} \mathrm{T}$-cells displays unique features. In mice with primary Sendai virus pneumonia, mediastinal LN cytotoxic T-lymphocytes (CTL) are predominantly L-selectin ${ }^{+}$ throughout infection and recovery, while CTL in the respiratory tract are largely L-selectin (Hou and Doherty, 1993). Memory CTL then revert to an L-selectin ${ }^{+}$phenotype (Tripp $e$ t al., 1995). There are conflicting data regarding L-selectin expression by CTL during allograft responses. In allografted sheep, alloantigen-specific $\mathrm{CD} 8^{+}$blasts recirculating from the draining $\mathrm{LN}$ are $\mathrm{L}$ selectin' (Verhagen et al., 1995); however, the range of expression is broad among memory cells, implying that, with time, L-selectin is down-regulated, perhaps to divert memory cells away from PLN and preferentially toward the site of the allograft. In contrast, allospecific cytolytic activity in mice is associated with the L-selectin $\mathrm{CD}_{4} 4^{+}$, but not the L-selectin ${ }^{+} \mathrm{CD} 44^{+}$, subset of effector cells (Mobley and Dailey, 1992). Moreover, L-selectin down-regulation is reversible, because most alloreactive memory cells are L-selectin ${ }^{+} \mathrm{CD} 44^{+}$(Mobley et al., 1994). L-selectin cells, taken during the effector phase of the rejection response and placed in culture in the absence of exogenous stimulation, revert to the L-selectin ${ }^{+}$phenotype, reflecting the results of Lepault et al. (1994). The question, then, is whether $\mathrm{L}$-selectin ${ }^{+} \mathrm{CD} 8^{+}$effector cells become L-selectin` memory cells (Verhagen et al., 1995), or L-selectin-CD8 ${ }^{+}$effector cells become L-selectin ${ }^{+}$ memory cells (Mobley et al., 1994). Differences in animal models and experimental details may at least partially explain this discrepancy.

\section{(D) TISSUE-SPECIFIC HOMING OF MEMORY T- CELLS}

Unlike naïve T-cells, memory T-cells do not recirculate homogeneously but instead display a propensity to home to a particular tissue or organ, such as skin, lung, or gut (Mackay, 1992; Springer, 1994). Induction of tissuespecific adhesion receptors is apparently a consequence of antigen priming in $\mathrm{LN}$ associated with different tissues, so that T-cells are imprinted to return to these tissues later. Local factors present in the microenvironment, rather than antigen directly, mediate adhesion molecule up-regulation. Since many foreign antigens are limited to particular tissues, the ability of T-cells specific for these antigens to home to the relevant tissue makes immune surveillance economical and efficient.

\section{(1) Skin-homing lymphocytes}

T-cell homing to skin is largely mediated by interactions between CLA on memory T-cells and E-selectin on endothelium (Berg et al., 1991; Shimizu et al., 1991) (Fig. 2). Greater than $90 \%$ of T-cells associated with skin express CLA, while $\mathrm{CLA}^{+}$cells represent less than $10 \%$ of peripheral blood T-cells. Generation of the CD45RA ${ }^{\circ} \mathrm{CD} 45 \mathrm{RO}^{+} \mathrm{CLA}^{+} \mathrm{L}$-selectin ${ }^{+}$phenotype correlates with conversion of naïve T-cells to effector cells in peripheral lymphoid tissues, being induced to a lesser extent in tonsil and other LN with mixed peripheral mucosal characteristics, and virtually not at all in mucosal LN (Picker et al., 1993b). A current model proposes that T-cells thus activated to express CLA are recruited to cutaneous sites (via CLAVE-selectin interactions), where local factors such as TGF- $\alpha 1$ and IL-6 further augment CLA expression (Picker et al., 1993b). Pro-inflammatory cytokines such as $\mathrm{IL}-1$ and TNF- $\alpha$ induce E-selectin (as well as VCAM-1 and ICAM-1) expression on endothelium (reviewed in Bevilacqua, 1993), enhancing T-cell infiltration into inflamed cutaneous tissue. $\alpha 4 \beta 1$ and LFA-1, in conjunction with E-selectin, appear to mediate in vitro transendothelial migration across activated HUVEC (Babi et al., 1995). E-selectin engagement of CLA may be a prerequisite for integrin activation. Unlike HUVEC, there is little expression of VCAM-I in skin endothelium, so that in vivo, LFA-1 may be more relevant than $\alpha 4 \beta 1$.

\section{(2) Gut-homing lymphocytes}

T-cells expressing $\alpha 4 \beta 7$ home to Peyer's patches and intestine as a consequence of binding to MAdCAM-1 (Berlin et al., 1993; Hamann et al., 1994). MAdCAM-1 is expressed on endothelium in mucosal tissues such as Peyer's patches and intestinal lamina propria (reviewed 
in Springer, 1994). MAdCAM-1, via its mucin-like domain, also mediates initial T-cell tethering by L-selectin (Berg et al., 1993), as described above.

Recent studies have dissected the role of $\alpha 4 \beta 7$ in lymphocyte homing to Peyer's patch HEV. While naïve lymphocytes rely primarily on $\mathrm{L}$-selectin, and to a lesser extent $\alpha 4 \beta 7$, for initial contact with endothelium, effector/memory T-cells that have up-regulated $\alpha 4 \beta 7$ expression (and down-regulated L-selectin) are able to utilize $\alpha 4 \beta 7$ for this purpose (Bargatze et al., 1995). In both cases, subsequent $\alpha 4 \beta 7$-mediated rolling and sticking precede, and appear to be necessary for, LFA-1-mediated tight binding and diapedesis (Fig. 2). This reliance on $\alpha 4 \beta 7$ is probably indirect, i.e., it provides a mechanism for slowing the T-cell in order for it to respond to local vascular signals required for LFA-1 activation. Furthermore, $\alpha 4$ integrins, in general, appear to be able to mediate initial tethering of T-cells, since both $\alpha 4 \beta 1$ and $\alpha 4 \beta 7$ were shown to mediate rolling on VCAM- 1 and MAdCAM-I (Berlin et al., 1995). The argument that $\alpha 4 \beta 7$ is capable of initiating lymphocyte rolling is strengthened by observations that, like L-selectin, this integrin is localized to microvillous projections (Berlin et al., 1995), which are the initial sites of leukocyte-endothelium contact.

A subset of predominantly $C D 8^{+}$mucosal T-cells, the intra-epithelial lymphocytes (IEL), are localized on the external surface of the basement membrane at the basolateral surfaces of epithelial cells in mucosal tissues, such as gut, as well as nasal, oral, and genito-urinary tracts (Parker et al., 1992). The hallmark IEL integrin is $\alpha E \beta 7$, which mediates the adhesion of IEL to epithelial cells (Cepek et al. 1993) by binding to E-cadherin (Cepek ot al., 1994; Karecla et al., 1995). Both LFA-1 and $\alpha E B 7$ appear to be important for IEL adhesion (Fig. 2). However, they are inversely regulated by TGF- $\alpha 1$ produced by epithelial cells, $\alpha E \beta 7$ being up-regulated and LFA-1 down-regulated. Cepek et al. (1993) propose a migratory route in which IEL first adhere to vascular ECS, migrate across the endothelium, through the lamina propria, and thence to the epithelium. Inverse regulation may be necessary to arrest LFA-1-mediated migration of IEL once they have reached their intra-epithelial destination and anchor them, via $\alpha E \beta 7$, to the basolateral membrane of epithelial cells. LFA-1 does not appear to play a role in adhesion of IEL to intestinal epithelium, since an anti-LFA-1 mAb did not inhibit this cellular interaction (Cepek et al., 1994). Interestingly, the B2 integrin p150,95 is expressed in mice on approximately half of all IEL in an activation-dependent manner (Huleatt and Lefrançois, 1995), but not on T-cells in lymphoid compartments. However, the specific function of p150,95 on IEL has yet to be elucidated. The mechanism whereby IEL home to the gut is at present unclear. It has been proposed that the adhesion molecule CD31 may play a role in IEL homing, insofar as it is expressed predominantly on $C D 8^{+}$cells and induces preferential binding to VCAM-1 via a4ß31 (Tanaka et al., 1992), an interaction which appears to be necessary for T-cell homing to the gut (Issekutz, 1993). Whether CD31 also mediates gut tropism via $\alpha E \beta 7$ remains to be determined. $C D 31$ has recently been shown to be a ligand for the $\alpha v \beta 3$ integrin and, as such, may mediate heterophilic interactions between leukocytes and endothelium (Piali et al., 1995). In contrast, CD31 is expressed by approximately $50 \%$ of peripheral blood lymphocytes, which are almost exclusively CD45RA ${ }^{+}$, and studies indicate that among peripheral blood lymphocytes, CD31 expression appears to be irrelevant to HUVEC transmigration (Bird et al., 1993).

TCR- $\alpha \delta^{+}$cells localize primarily to epithelial tissues and comprise a subset of gut lymphocytes. The trafficking of TCR- $\alpha \delta^{+}$cells has not been studied as extensively as that of TCR- $\alpha \beta^{+}$cells, but evidence indicates that tissue tropism of this T-cell subset may be ontogenetically determined and less reliant on antigen conditioning. For example, TCR- $\alpha \delta^{+}$(but not TCR- $\alpha \beta^{+}$) IEL are found in epithelium from fetal as well as germ-free mice (cited in Cepek et al., 1993). TCR- $\alpha \delta^{+}$cells express high levels of $L-$ selectin and home preferentially to LN HEV regardless of their tissue origin (Washington $e t$ al., 1994).

In summary, naïve and effector/memory T-cells follow distinct migration routes. This is achieved, on the one hand, by the differential expression of a number of adhesion molecules, including selectins, integrins, IgSF members, and proteoglycans, on naïve, effector, and memory T-cells, and, on the other hand, by the restricted expression patterns of adhesion molecule ligands on endothelium. Thus, adhesion and subsequent transendothelial migration occur in a tissue-specific manner. This is important for the recruitment of naïve cells to secondary lymphoid tissues such as PLN, spleen. Peyers patches, and tonsils, where there are optimal conditions for antigenic stimulation, and for memory cells to be guided to tissues where they are most likely to see those antigens that they have previously encountered. thereby maximizing the efficiency with which T-cells patrol the body.

\section{(V) T-lymphocyte Interactions with Extracellular Matrix}

The ECM is a complex and highly organized mixture of fibrous proteins (such as collagens, laminin, and FN) and glycosaminoglycans (such as HA and chondroitin sulfate) (Mignati and Rifkin, 1993). With the exception of $\mathrm{HA}$, the major glycosyaminoglycans found in the ECM are covalently bound to protein backbones to form proteoglycans. The role of the ECM in providing a structural scaffold for cell growth and development is well-established. For example, the basement membrane, a specialized type of ECM that consists primarily of type IV colla- 
gen and laminin, serves as a barrier between epithelial and ECs and the underlying tissue. However, recent studies have clearly revealed the ECM to possess multiple functions in addition to that of a structural framework. For circulating cells, such as lymphocytes, the ECM serves multiple purposes. In this section, we highlight several functions of the ECM relevant to T-cell migration and activation: (1) ECM proteins as specific ligands facilitating T-cell diapedesis; (2) ECM proteins as T-cell chemoattractants; (3) T-cell signal transduction initiated by interaction with ECM components or soluble factors "presented" to T-cells by the ECM; (4) production of ECM proteins by T-cells; and (5) tissue-specific differences in the ECM that may contribute to tissue-specific T-cell migration and/or signal transduction.

\section{(A) The EXTRACELlULar MATRIX AND T-LYMPHOCYTE MIGRATION}

\section{(1) Diapedesis}

The final step in the successful exit of lymphocytes out of the bloodstream into lymphoid organs or non-lymphoid tissue sites involves T-cell penetration through the underlying basement membrane and into the surrounding interstitial stroma (Ager, 1994). The precise mechanism by which T-cells carry out this process of diapedesis or transmigration remains poorly defined, although it is now clear that T-cells express several functionally active receptors that can interact with major components of the ECM. Resting peripheral T-cells express the $\alpha 4 \beta 1$ and $\alpha 5 \beta 1$ integrins, which have been shown to mediate activation-dependent T-cell adhesion to FN (Shimizu et al., 1990C). These two integrins bind to distinct sites on the FN molecule, the CS-1 sequence in the type III connecting segment of the major cell adhesion domain (for $\alpha 4 \beta 1$ ) and the arg-gly-asp (RGD) sequence (for $\alpha 5 \beta 1$ ). The $\alpha 4 \beta 1$ and $\alpha 5 \beta 1$ integrins have also been reported to mediate activation-dependent binding of human T-cells to thrombospondin (TSP) (Yabkowitz et al., 1993), an adhesive protein that is secreted by activated ECs and activated platelets, and consequently found in high concentrations in the ECM in damaged and inflamed tissues (Mosher, 1990). An additional receptor that mediates the adhesion of resting T-cells to TSP has also been implicated, although the identity of this receptor(s) currently remains unknown. The $\alpha 6 \beta 1$ integrin is also expressed on resting T-cells and mediates T-cell adhesion to laminin (Shimizu et al., 1990c), a major component of the basement membrane. Although resting peripheral T-cells do not bind to collagen in in vitro adhesion assays, activation of T-cells in vitro results in induction of expression of the $\alpha 2 \beta 1$ integrin (Hemler, 1990) and subsequent $\alpha 2 \beta 1$-mediated binding to collagen (Goldman et al., 1992). CD44 is also expressed at high levels on resting human T-cells (Lesley et al., 1993). The HA-binding activ- ity of CD44 expressed on T-cells appears to be tightly regulated, since resting CD44-positive T-cells do not bind to soluble or immobilized HA (Lesley et al., 1993). Various modes of activating T-cells in vitro failed to induce HA binding, although stimulation of T-cells with certain CD44-specific mAbs did result in HA binding (Lesley et al., 1993). Furthermore, transient T-cell binding of HA, following an in vivo allogeneic response, has been demonstrated (Lesley et al., 1994), suggesting a physiological relevance for T-cell interactions with HA. ICAM-I, which is expressed at low levels on resting T-cells, has also been reported to be a HA receptor (McCourt et al., 1994). The physiological significance of this finding remains to be established

Although numerous in vitro studies have established that T-cells express multiple functional ECM receptors, the relevance of these cell-ECM interactions during the specific process of diapedesis is not as well established. Both specific antibodies and peptides containing the relevant $\alpha 4 \beta 1$ and $\alpha 5 \beta 1$ binding sequences on FN $(C S 1$ and RGD, respectively) have been shown to inhibit T-cell adhesion to, and migration through, cultured high EC in vitro (Ager and Humphries, 1990; Szekanecz et al., 1992; Hourihan et al., 1993). These studies suggest that FN is accessible and available for interaction with T-cells interacting with endothelium in the bloodstream. Consistent with this hypothesis, numerous studies have shown that treatment with FN peptides or integrin-specific antibodies can inhibit T-cell-mediated immune responses in vivo (Ferguson et al., 1991; Ferguson and Kupper, 1993; Hershkoviz et al., 1994b; Hines et al., 1994). Although the general conclusion that can be drawn from these studies is that these inhibitory reagents inhibit T-cell migration or movement rather than T-cell activation, the precise mechanism by which these reagents inhibit T-cell trafficking remains difficult to establish in these models.

\section{(2) Extracellular matrix proteins as chemoattractants}

In addition to serving as specific adhesive substrates, ECM components may also promote T-cell migration by serving as specific chemoattractants. Studies with several T-cell lines and PMA-stimulated T-cells in Boyden chambers have shown both haptotactic and chemotactic migration of these cells on FN, collagen type IV, and laminin (Hauzenberger et al., 1994). These studies also suggested that migration of specific T-cell lines on FN was mediated by either $\alpha 4 \beta 1$ or $\alpha 5 \beta 1$ but not both integrins, even though these cells expressed both of the FNbinding integrins (Hauzenberger et al., 1994). Locomotion of T-cells in a three-dimensional collagen matrix has also been investigated (Friedl et al., 1995). Recent studies in this system have shown that growth of T-cells in this collagen matrix results in the generation of a novel T-cell population characterized by expression of the $\alpha 2 \beta 1$ integrin, which is typically not expressed on 
human peripheral T-cells, and low expression of CD44 and L-selectin (Friedl et al., 1995). These results provide additional evidence that T-cell interactions with the ECM are of relevance to differentiation-induced expression of adhesion molecules. The relevance of $\alpha 2 \beta 1$ expression for T-cell movement in this matrix is suggested by the ability of an a2-specific mAb to inhibit locomotion.

Recent findings, demonstrating that T-cell adhesion can be regulated by chemokines bound in a biologically active state to proteoglycans (Tanaka et al., 1993b), suggest that the ECM may serve as a reservoir for additional chemoattractants above and beyond the ECM proteins that themselves facilitate T-cell migration. The concept of the ECM as a "cytokine reservoir" has several significant implications for our understanding of the role of the ECM in T-cell migration. First, immobilization of soluble factors in the ECM may be critical for providing a sufficiently high local concentration to allow T-cells to respond to the chemotactic factor. Second, immobilization of such soluble factors in the ECM may result in the generation of chemotactic gradients that may be necessary for facilitating T-cell transmigration through ECs and into the surrounding tissue. Third, this concept illustrates that the biological properties of the ECM are likely to be significantly different in various anatomic locations, since the cytokine milieu differs from tissue to tissue. This may be particularly relevant to our understanding of T-cell migration into sites of inflammation, where the production of cytokines is a biological response of many different cell types involved in inflammation.

\section{(3) Lymphocyte Transmigration and ECM Degradation}

Studies of tumor cells have demonstrated that their production of enzymes capable of degrading ECM components plays a vital role in the cells' ability to metastasize (Mignati and Rifkin, 1993). In addition to tumor cell invasion, enzymatic degradation of the ECM has also been shown to be important in tissue remodeling, during development as well as during wound healing and inflammation, and in angiogenesis (Woessner, 1991). Given that T-cells, during the process of migration, must successfully complete the same types of adhesive interactions as do metastasizing tumor cells, it is not surprising to find that: (1) T-cells produce ECM-degrading enzymes; (2) T-cell production of ECM-degrading enzymes can be regulated by cell-ECM interactions; and (3) ECM-degrading enzymes have been shown to play a role in T-cell migration (Fig. 3).

Several recent studies have documented regulated production, by T-cells, of gelatinase A $(72-\mathrm{kD}$ collagenase, matrix metalloproteinase-2), which degrades type IV collagen, and gelatinase B (92-kDa collagenase, matrix metalloproteinase-9), which degrades type $V$ collagen. Leppert et al. (1995) reported constitutive expression of

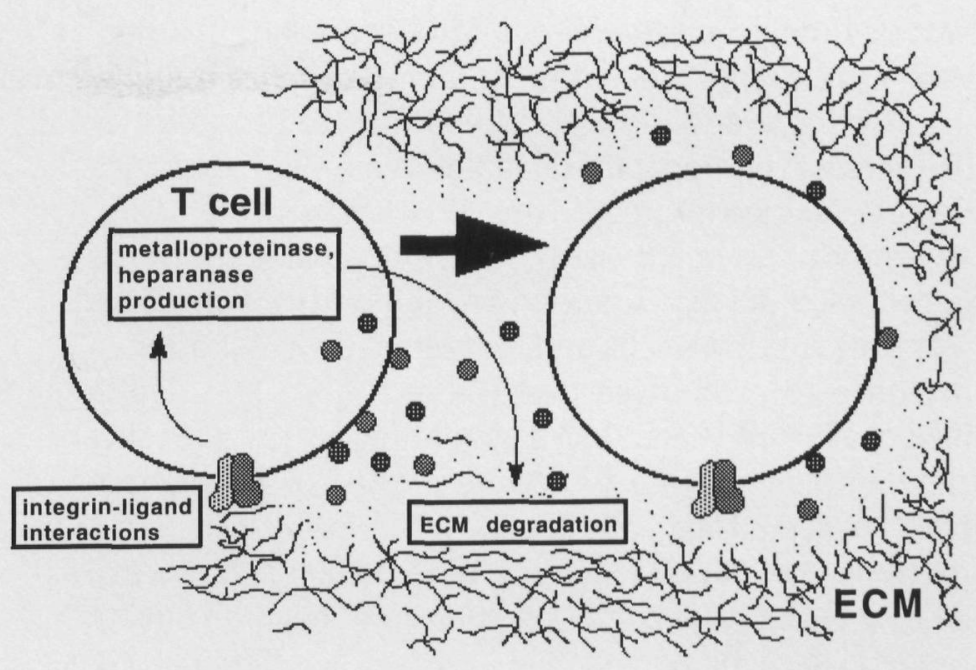

Figure 3. Lymphocyte transmigration and extracellular matrix degradation. Adhesion of T-cells to ECM components such as FN mediates signals that induce the expression of matrix-degrading enzymes such as metalloproteinases and heparanase. The action of these enzymes permits the T-cells to traverse the basement membrane. See text for details.

gelatinase B by resting T-cells. Stimulation of T-cells with IL-2 resulted in increased gelatinase B expression as well as induced expression of gelatinase A (Leppert et al., 1995). The relevance of gelatinase production for T-cell migration is suggested by the ability of a matrix metalloproteinase inhibitor to block the in vitro migration of $\mathrm{T}$ cells across a filter coated with Matrigel, a commonly used commercial reagent derived from a mouse tumor cell line that resembles basement membrane in that it contains predominantly type IV collagen and laminin (Leppert et al., 1995). Inhibition of gelatinase was also shown to block the migration of a mouse T-cell clone through an endothelial monolayer expressing VCAM-1 (Romanic and Madri, 1994). Interestingly, these investigators also demonstrated the presence of gelatinase on the surfaces of these T-cells, and propose that cell-surface association of matrix-degrading enzymes, specifically in the pericellular region, may be necessary for T-cell migration into tissue (Romanic and Madri, 1994).

The expression of matrix metalloproteinases such as gelatinases A and B has been shown to be regulated by integrin receptor-ligand interactions. $\alpha 4 \beta 1$ interaction with VCAM-1 has been shown to induce gelatinase expression in mouse T-cells (Romanic and Madri, 1994). These results are consistent with studies conducted using other cell types demonstrating that integrin engagement can modulate the expression of matrix metalloproteinases (Seftor et al., 1992; Seltzer et al., 1994; Huhtala et al., 1995). Thus, a regulatory network exists whereby cell adhesion generates integrin-mediated signals that serve to induce expression of enzymes involved in degrading the surrounding matrix (Fig. 3). The studies of gelatinase expression in T-cells suggest that this mode of regulation provides an elegant system whereby these 
enzymes are produced when matrix degradation is necessary to traverse the basement membrane successfully.

T-cell activation has also been reported to result in the release of heparanase, an enzyme that degrades heparan sulfate proteoglycans (Vlodavsky et al, 1992) Treatment of mice with heparin, which inhibits heparanase activity, was found to inhibit the expression of heparanase by T-cells and to inhibit T-cell migration in response to a DTH reaction (Lider et al., 1990). These results also implicate ECM degradation as critical to successful T-cell migration. Recent studies of heparanase have suggested that conditions in the local tissue environment, specifically $\mathrm{pH}$, can modulate the biological activity of this molecule. Degradation of heparan sulfate proteoglycans by heparanase occurred at acidic $\mathrm{pH}$ values ranging from 5.4 to 6.8 , with maximal enzymatic activity occurring at $\mathrm{pH}$ 6.2-6.8 for heparanase isolated from activated T-cells (Gilat et al., 1995). Activity was minimal at $\mathrm{pH}$ values above and below this range. Although not enzymatically active, heparanase was able to bind to $\mathrm{ECM}$ at $\mathrm{pH} 7.2$ and could mediate the adhesion of resting T-cells, presumably by T-cell heparan sulfate proteoglycans binding to the ECM-immobilized heparanase. Thus, this molecule can serve as either a matrix-degrading enzyme or an adhesive substrate, depending on the local environmental conditions. It will be important, in the future, to determine if other adhesive factors exhibit similar multidimensional properties.

\section{(B) The eXtracellular MatriX AND LYMPHOCYTE MOVEMENT IN TISSUE}

In addition to playing an important structural and regulatory role in T-cell attachment to and transmigration through ECs, the ECM also clearly regulates T-cell movement in tissue. Activation of T-cells, either via the antigen-specific TCR or via several other cell-surface receptors that have been implicated as being important in antigen-specific T-cell responses, has been shown to result in a rapid and transient increase in $\beta 1$ integrinmediated adhesion of T-cells to FN and laminin (Shimizu et al., 1990c; Chan et al., 1991; Mobley et al., 1993). The ability of T-cell activation to increase integrin-mediated T-cell adhesion rapidly to the surrounding ECM has been proposed to be important in the retention and localization of T-cells at the site of antigen encounter (Shimizu et al., 1990a,c). This hypothesis is consistent with studies demonstrating the preferential retention of antigen-specific T-cells in LN draining the site of antigen administration during the first one to two days after introduction of antigen (reviewed in Picker and Butcher, 1992). T-cell activation during an allogeneic response, in vivo, has also been shown transiently to activate CD44-mediated binding of T-cells to HA, providing additional evidence that activation-dependent adhesion to the surrounding ECM is likely to play a critical role in the generation and main- tenance of a T-cell-specific immune response in tissue (Lesley et al., 1994).

Expression on the cell surfaces of ECM receptors not normally found on the majority of peripheral T-cells may result in the long-term retention of specific T-cell populations in a particular anatomic location. The identification of $\alpha 1 \beta 1$-positive T-cells in lung epithelium has led to the suggestion that $\alpha 1 \beta 1$ may play a role (perhaps by binding to collagen) in the retention of these cells in the lung (Saltini et al., 1988). Recent studies demonstrating the expression of the $\alpha E \beta 7$ integrin on IEL have also led to the hypothesis that the retention of this unique population of T-cells in this site may be due, in whole or in part, to $\alpha E \beta 7$ binding to E-cadherin (Cepek et al., 1993 , 1994; Parker et al., 1992). This concept of specific retention of T-cell populations by ECM-mediated interactions may also be applicable to our understanding of autoimmune diseases such as arthritis, where the expression of constitutively active integrin receptors due to chronic activation in vivo has been proposed to be one mechanism by which autoreactive T-cells are retained in the arthritic joint (Laffón et al., 1991; Rodriguez et al., 1992). Thus, interactions with the ECM may play a role in inhibiting, as well as facilitating, T-cell movement in tissue sites.

\section{(C) THE EXTRACELLULAR MATRIX AND T-CELL ACTIVATION}

The process of T-cell activation, in response to an encounter with a foreign antigen, involves the generation of a complex array of intracellular signals mediated by cell-surface receptors that ultimately leads to T-cell proliferation and the generation of an appropriate effector function, such as cytokine secretion or cytotoxicity. While the role of T-cell interactions with other cells, such as antigen-presenting cells, in the process of T-cell activation has been extensively studied and appreciated, it is now clear that the surrounding ECM also plays a role in T-cell responses to foreign antigen. While we have discussed the role that the ECM plays in facilitating T-cell movement into and through tissue. T-cell interactions with the ECM also play a role in T-cell activation by the generation of ECM-induced signaling events that can modulate antigen-specific T-cell responses. Thus, the ECM represents a rich milieu of information that T-cells access to ensure that a specific and appropriate response to a foreign antigen in that site is generated.

\section{(1) ECM-mediated signal transduction in T-cells}

The potential role of the ECM in T-cell signal transduction first came into prominence when purified ECM proteins, most notably FN, were evaluated for their ability to facilitate T-cell proliferation induced by antibody crosslinking of the CD3/T-cell receptor (CD3/TCR) complex. These studies were part of a large interest in 
immunology in identifying molecules capable of providing "co-stimulatory" signals, defined as signals that could induce T-cell proliferation in combination with CD3/TCR cross-linking when CD3/TCR cross-linking by itself was insufficient to do so (van Seventer et al., 1991). Initial studies found that under conditions where purified T-cells could not proliferate in response to CD3-specific mAbs immobilized on a plastic surface, co-immobilization of purified FN or laminin with the CD3-specific $\mathrm{mAb}$ now resulted in vigorous $\mathrm{T}$-cell proliferation (Matsuyama et al., 1989; Davis et al., 1990. Shimizu et al., $1990 \mathrm{~b}$ ). The co-stimulatory effects of ECM proteins have also been observed with thymocytes (Chang et al., 1995; Ticchioni et al, 1995), consistent with other studies demonstrating a role for the ECM in T-cell development in the thymus (Utsumi et al., 1991; Sawada et al., 1992; Salomon et al., 1994). In aggregate, these studies suggest that intracellular signals generated upon interaction of $\beta 1$ integrins with either FN or laminin can synergize with the "primary" signal generated by CD3/TCR cross-linking and result in T-cell proliferation.

The co-stimulatory signal provided by ECM proteins in this system was most effective when the CD3-specific $\mathrm{mAb}$ and the ECM protein were immobilized on the same plastic surtace. This led initially to the hypothesis that the ECM proteins did not transduce a unique intracellular signal but rather that the adhesive properties of the ECM protein enhanced the interaction of the T-cells with the CD3-specific mAb, resulting in a stronger primary signal and T-cell proliferation. This particular objection to the role of ECM in T-cell-mediated signal transduction has now been overshadowed by a large and ever-increasing body of evidence, in multiple cell systems, that ECM receptors can generate intracellular signals upon interaction with ECM proteins. Analysis of integrin-mediated signal transduction has been the most extensive and has recently been reviewed (Clark and Brugge, 1995). We highlight here the most relevant recent studies pertaining specifically to $\mathrm{T}$-cell activation and the role of the ECM in this process.

Direct biochemical evidence that cell-ECM interactions lead to the generation of intracellular signals is now available. In fibroblasts and several other non-lymphoid cell lines, engagement of $\beta 1$ integrins by either specific MAb or ECM ligands leads to the tyrosine phosphorylation of a 125 -kDa protein, which has been identified as the tyrosine kinase focal adhesion kinase (FAK) (reviewed in Richardson and Parsons, 1995; Schaller and Parsons, 1994). FAK localizes to the points of contact (focal adhesions) between these adherent cells and the underlying ECM, and has been shown to interact physically with the cytoplasmic domain of the $\beta 1$ chain (Schaller and Parsons, 1994). Although T-cells are nonadherent cells and do not form classic focal adhesions when interacting with ECM proteins, $\beta 1$ integrin-mediat- ed phosphorylation of FAK in a T-cell line has been reported (Nojima et al., 1995). MAb cross-linking of the CD3/TCR has also been reported to result in tyrosine phosphorylation of a novel substrate with homology to FAK that has been named fakB (Kanner et al., 1994). It is currently not known whether fakB is tyrosine-phosphorylated in response to $\beta 1$ integrin-mediated interactions with the ECM.

Studies of $\beta 1$ integrin-mediated interactions of $\mathrm{T}$ cells with FN have demonstrated rapid tyrosine phosphorylation of proteins in the molecular weight range of 105-115 kDa (Nojima et al., 1992; Ostergaard and Ma, 1995). The precise identity of these proteins remains unknown, although one report shows that they are not recognized by FAK-specific antibodies (Nojima et al., 1995). These tyrosine kinase substrates may be of particular relevance to our understanding of integrin-mediated signaling in lymphocytes, since $\beta 1$ integrin engagement has been shown to result in tyrosine phosphorylation of substrates of similar molecular weight in B-cells and NK cells as well as primary T-cells. T-cell lines, and T-cell clones (Freedman et al., 1993; Rabinowich et al, 1995). Proteins of a similar molecular weight have also been reported to be tyrosine-phosphorylated in response to engagement of the $\alpha v \beta 3$ vitronectin receptor in $\alpha \beta$ T-cell clones (Brando and Shevach, 1995). Clearly, the issue of the functional significance of integrin-mediated tyrosine phosphorylation in T-cell activation will require additional analysis, including: ( 1 ) the identification of these novel 105-115-kDa substrates that do not appear to be FAK: (2) the precise role of both FAK and fakB in T-cell activation; and (3) identification of other substrates that may be tyrosine-phosphorylated in response to T-cell interactions with ECM. For example, adhesion of fibroblasts to FN results in tyrosine phosphorylation of the cytoskeletal protein paxillin (Clark and Brugge, 1995), as well as tyrosine phosphorylation and activation of mitogen-activated protein (MAP) kinases (Morino et al., 1995). Engagement of the $\alpha v \beta 3$ integrin on mouse T-cells has been shown to result in tyrosine phosphorylation of the CD3 $\beta$ chain (Sturmhöfel et al., 1995). The relevance of such findings for our understanding of the role of the ECM in T-cell activation awaits further analysis

Other lines of biochemical and molecular evidence for ECM-mediated signal transduction besides tyrosine phosphorylation are also now available. A unique mAb specific for the $\beta I$ integrin chain has been shown to increase levels of intracellular cAMP in T-cells stimulated by CD3-specific or CD2-specific mAbs (Groux et al.. 1989). Interaction of T-cells with FN has also been shown to result in induction of the AP-1 transcription factor (Yamada et al., 1991), which notably is involved in induction of IL-2 expression upon T-cell activation. Recent studies have provided additional evidence that cell-ECM interactions can lead to induction of gene expression. 
Antibody engagement of the $\alpha 4 \beta$ I integrin on monocytes induced expression of the tissue factor gene as well as the cytokine TNF- $\alpha$ (Fan et al., 1995). These studies are consistent with findings that interaction of T-cells and monocyte, with ECM, purified FN, or laminin, resulted in TNF- $\alpha$ production by these cell types (Hershkoviz et al., 1993). Interestingly, this study also reported enhanced ECM-induced TNF- $\alpha$ production by T-cells and monocytes if the ECM was first damaged by physical scraping. Interaction of mouse T-cell clones with the ECM via the $\alpha v \beta 3$ integrin has been shown to be required for constitutive cytokine production by these clones in vitro (Moulder et al., 1991; Sturmhöfel et al., 1995). As discussed above, contact of cells with ECM proteins has also been shown to result in induction of expression of matrix-degrading enzymes (Seftor et al., 1992; Seltzer $e t$ al., 1994; Huhtala et al., 1995). Co-stimulation of T-cells with a combination of CD3-specific mAbs and purified ICAM-1 or VCAM-1 resulted in the induction of expression of the B7-1 and B7-2 counter-receptor CTLA-4 (Damle $e$ al., 1994), raising the possibility that T-cell costimulation by ECM proteins may similarly result in the expression of novel cell-surface molecules. Such results clearly support the hypothesis that ECM proteins and other co-stimulatory molecules may play a vital role in dictating the specificity of T-cell activation and resulting effector functions (van Seventer et al., 1991). Finally, recent studies have also implicated $\beta 1$ integrins in the regulation of apoptosis (Koopman et al., 1994; Boudreau et al., 1995).

It should be noted here that it is currently not known if all of the ECM-mediated signaling events that have been reported to occur in non-lymphoid cells also occur upon engagement of the same adhesion receptor expressed on T-cells. As an example, recent studies of $\alpha \vee \beta 3$-dependent interactions of osteoclasts with the bone matrix protein osteopontin have demonstrated that osteopontin can induce the activity of the lipid kinase phosphatidylinositol 3-kinase (PI 3-K) (Hruska et a!., 1995), an intracellular enzyme that has been implicated in a wide variety of cellular responses, including membrane ruffling and growth-factor-dependent mitogenesis (Kapeller and Cantley, 1994). These studies also provide evidence for an integrin-associated signaling complex in osteoclasts consisting minimally of PI 3-K, the c-src proto-oncogene product, and FAK (Hruska et al., 1995). It remains to be determined whether $\alpha v \beta 3$ expressed on T-cells is also associated with such a signaling complex, and whether $\alpha v \beta 3$ engagement on $\mathrm{T}$ cells by one of its ECM ligands (such as vitronectin or perhaps even osteopontin), leads to activation of similar intracellular signaling mediators.

Although considerable progress has been made in our understanding of ECM-mediated signal transduction in T-cells, much remains to be elucidated. For example, the precise signaling pathways utilized by integrins and other ECM receptors that result in biologically relevant responses, such as cytokine production, expression of novel cell-surface molecules, and apoptosis, remain poorly defined. The gulf remains large between early signaling events induced by the ECM, such as tyrosine phosphorylation, and the later events, such as induction of gene expression. Potential points of convergence and divergence between the known signaling pathways utilized by the antigen-specific TCR, and the signal transduction pathway(s), induced by T-cell interactions with the ECM, also remain unclear. However, one recent study has demonstrated that constitutive cytokine production mediated by the $\alpha v \beta 3$ integrin in a mouse $\alpha \beta$ T-cell clone requires the presence of the $\zeta$-chain of the CD3/TCR complex, suggesting that signaling by this integrin involves a key component of the CD3/TCR in the absence of antigen-specific recognition (Sturmhöfel et al., 1995). These investigators propose that interactions of T-cells with the surrounding ECM lead to integrin-mediated T-cell activation that, in the absence of TCR engagement, can lead to T-cell cytokine production. Such constitutive cytokine production may be relevant to our understanding of the role of T-cells in inflammation. It remains to be determined if this clear point of convergence in integrin-mediated and TCR-mediated signaling in this system is unique to the $\alpha v \beta 3$ integrin, or is perhaps a more common feature of ECM-mediated signal transduction in Tcells.

\section{(2) The extracellular matrix as a cytokine reservoir}

The hypothesis that soluble factors such as chemokines can modulate T-cell adhesion to endothelium, by binding to cell-surface glycosaminoglycans and being "presented" to circulating T-cells, raises the possibility that the ECM, which is rich in proteoglycans, may also serve as a reservoir for biologically active soluble factors. Gilat et al. (1994) demonstrated that the chemokines, RANTES and MIP- $1 \alpha$, can be bound by ECM, and that the ECMbound chemokines can modulate T-cell adhesion to ECM. These findings extend the regulatory effects of proteoglycan-immobilized chemokines to T-cell interactions with ECM, as well as T-cell interactions with endothelium

Binding and presentation of biologically active factors by the ECM to T-cells have also been extended by findings that TNF- $\alpha$ binds to the N-terminal domain of $\mathrm{FN}$, and that bound TNF increases the adhesion of PMAstimulated T-cells to FN (Alon et al., 1994; Hershkoviz et al., 1994a). Thus, although TNF by itself is not able to induce integrin-mediated T-cell adhesion to FN, it can enhance adhesion induced by a stimulus that increases $\beta 1$ integrin activity, such as PMA. Thus, the ECM may play several vital roles in facilitating the biological effects of TNF- $\alpha$ in inflammatory processes. First, the 
ECM can induce TNF- $\alpha$ secretion by T-cells, as well as monocytes (Hershkoviz et al., 1993). Second, the ECM can bind TNF- $\alpha$ once it has been produced (Alon et al., 1994), immobilizing it at the site of the response and perhaps maintaining TNF- $\alpha$ levels at a sufficiently high local concentration for it to be maximally effective. Finally, the ECM-bound TNF- $\alpha$ can enhance the adhesion of activated T-cells to the surrounding ECM (Alon et al., 1994; Hershkoviz et al., 1994a). This may serve two important roles: retaining activated T-cells at the site where the TNF- $\alpha$ is being produced, as well as further promoting additional TNF- $\alpha$ production by enhancing cellular interactions with the ECM. Thus, these studies suggest a regulatory loop, whereby the ECM plays a role not only in initiating cytokine production, but also in maximizing its biological effectiveness and ensuring its continued production (Fig. 4).

\section{(3) Modulation of lymphocyte activation 6y ECM proteins bound to cell surfaces}

A characteristic of ECM components such as FN, collagen, and laminin is the presence of multiple adhesionbinding sites on a single molecule. This potentially allows a single ECM protein to bind to several different proteins and cells. This, undoubtedly, is necessary for maintaining the structural network that constitutes the ECM. However, several groups have speculated that ECM proteins, particularly FN, might enhance cell-cell adhesion by the recognition of distinct binding domains by different cells, thereby allowing the FN to serve as a cellular "bridge" (Shimizu et al., 1990a; Hershkoviz et al., 1992). This is an appealing concept, since two different cells could potentially bind to one FN molecule, one utilizing the RGD binding site (via $\alpha 5 \beta 1$ ) and the other utilizing the CS1 sequence (via $\alpha 4 \beta 1$ ). The ECM, thus, might also serve to enhance interactions between T-cells and antigen-presenting cells. Although there is some evidence that FN can be found bound to the cell surfaces of T-cells (Hauzenberger and Sundqvist, 1993), the only evidence that ECM-mediated enhancement of cell-cell adhesion can modulate T-cell activation are studies demonstrating either enhancing or inhibitory effects of soluble FN on various T-cell proliferative responses in vitro (Klingemann et al., 1986; Easter et al., 1988; Rybski et al., 1989). The exact mechanism by which FN modulates T-cell activation in these systems has not been extensively analyzed, and thus, the functional relevance, if any, of cell-surface-bound ECM components to T-cell activation remains undefined.

\section{(4) Activation-dependent production of ECM components by lymphocytes}

T-cells have also been shown to be able to produce and secrete FN (Godfrey, 1990; Hershkoviz et al., 1992). Several properties of T-cell-derived FN have been report-

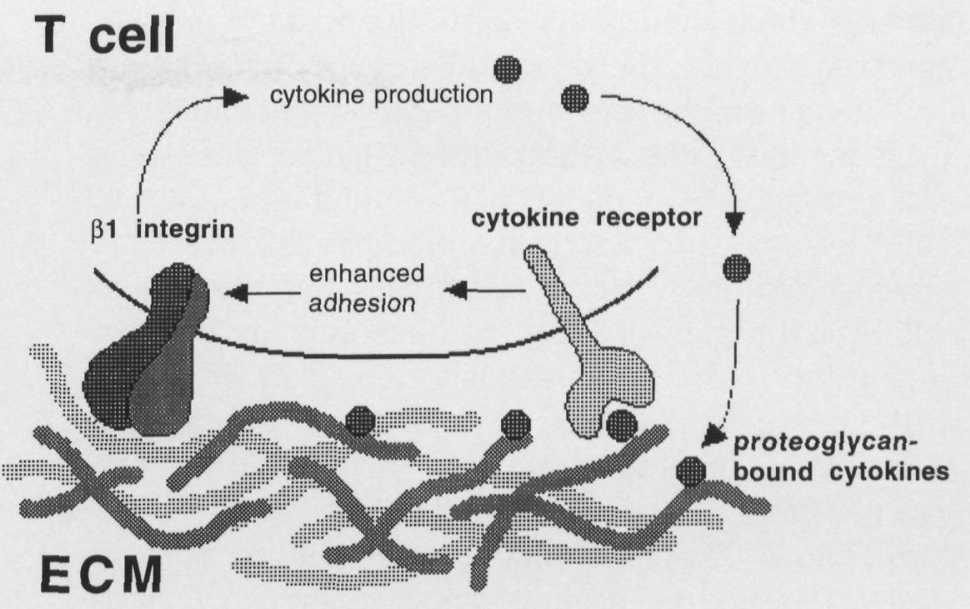

Figure 4. A cytokine-regulatory network involving $\beta 1$ integrins and the ECM. Cytokines released by T-cells and other cells can bind to proteoglycans in the ECM and subsequently facilitate T-cell migration. In addition, cytokines such as TNF- $\alpha$ can enhance adhesion of activated T-cells to ECM components such as FN. Enhanced T-cell interaction with the ECM, in turn, can lead to increased TNF- $\alpha$ production. See text for details.

ed, including: (1) agglutination of mononuclear phagocytes (Godfrey, 1990); (2) mediation of neutrophil and monocyte migration through collagen matrices; and (3) enhanced ability to mediate cell adhesion when compared with plasma FN (Hershkoviz et al., 1992). The functional relevance of T-cell production and synthesis of FN for our understanding of T-cell activation remains unclear, although the ability of T-cell activation to induce secretion of FN from T-cells (Hershkoviz et al., 1992) suggests that it may be of some importance.

\section{(D) FUNCTIONAL IMPLICATIONS OF ANATOMIC HETEROGENEITY IN EXPRESSION OF ECM COMPONENTS}

In addition to appreciating the relevance of the ECM, in general, to T-cell function, we must also now acknowledge that the ECM can exhibit tissue-specific heterogeneity. This can occur in several ways. First, as discussed in several of the preceding sections, proteoglycans and ECM glycoproteins, such as FN, can bind to soluble factors found in the local environment. Thus, differences in the cytokine milieu, found in one anatomic site versus another, can have a profound effect on both T-cell migration and the ensuing activation of those T-cells that have successfully entered that site. Second, there can be unique expression of ECM glycoproteins at certain sites. For example, the ECM protein tenascin has been shown to inhibit certain T-cell-proliferative responses, in vitro (Rüegg et al., 1989). Since tenascin can be produced by tumor cells, and can be found to be expressed at sites of tissue injury, these results suggest that local expression of tenascin may, for example, play a role in the response of the immune system to tumor cells. Third, multiple isoforms of both laminin and FN have been identified. 
Although the in vivo significance of these isoforms is still somewhat unclear, the gain or loss of specific cell adhesion domains in these isoforms suggests that differences in expression of these ECM protein isoforms, between tissues, may have an effect on T-cell migration and activation. One recent study used antibodies that specifically recognized $\mathrm{FN}$ molecules containing the alternatively spliced CSI region of FN to demonstrate that FN containing the $\alpha 4 \beta 1$ recognition site (CS1-containing FN) was found to be expressed on EC derived from the synovium of patients suffering from rheumatoid arthritis, but not from normal synovium (Elices et al., 1994). Furthermore, CS1-containing FN was found to be exclusively expressed in arthritic synovium on the lumenal surface of the endothelium, where it was capable of mediating the adhesion of T-cells expressing functionally active $\alpha 4 \beta 1$ integrins (Elices et al., 1994). These studies raise the intriguing possibility that $\alpha 4 \beta 1$-mediated adhesion of T-cells to CSI-containing FN, found on the lumenal surface of endothelium, may play a pivotal role in the migration of autoreactive T-cells in the synovial fluid, resulting in the generation of this chronic inflammatory condition (Elices et al., 1994). More generally, these results vividly illustrate that elucidation of the anatomic heterogeneity in the ECM, under both normal and diseased conditions, will likely lead to valuable new insights into our understanding of T-cell migration and activation.

\section{(VI) Clinical Relevance}

Adhesive interactions between T-cells and endothelium are crucial in the host's immune response to infections, inflammation, and other perturbations of the immune system. Unfortunately, these same adhesive interactions can occasionally lead to the development of many human diseases, including vascular thrombosis, diabetes, vasculitis, central nervous system (CNS) inflammation/encephalitis, asthma, tumor metastasis, arthritis, psoriasis, and transplant rejection. Once considered a bystander, the endothelium is now known to be at the center of events leading to an inflammatory lesion. Using recent molecular insights into the adhesion cascade, we are now in a position to begin to understand the events leading to the pathogenesis of many of the above diseases, and to begin to design rational therapeutic strategies to treat them. In this section, we highlight three Tcell-mediated clinical diseases that have been well-studied in the context of lymphocyte-endothelial adhesive interactions: rheumatoid arthritis (RA), psoriasis, and experimental autoimmune encephalomyelitis (EAE)

\section{(A) Rheumatold ARTHRITIS}

Although all humans have autoreactive B-and T-cells, normal regulatory mechanisms (genetic factors, pathogens, etc.) prevent these cells from reacting to self- antigens. It is only when these regulatory mechanisms fail that autoimmune disease occurs (Steinman, 1995). One of the most common autoimmune diseases is RA, a systemic autoimmune disease characterized by a chronic, symmetric, and erosive synovitis of peripheral joints (Wilder, 1993). Although the etiology of RA is unknown, basic research has provided a substantial understanding of the molecular and cellular aspects of pathogenesis. Rheumatoid synovitis involves many mediators and cell types, including the synovium, neutrophils, monocytes, macrophages, cytokines (IL-1, TNF, and IFN- $\beta$ ), ECs, and lymphocytes (Wilder, 1993). The rheumatoid synovial immunoreactive lesion is comprised of a mononuclear cell infiltrate (antigen-presenting cells) in close contact with $\mathrm{T}$ lymphocytes (Oppenheimer-Marks and Lipsky, 1995). The phenotype of these synovial tissue lymphocytes is consistent with memory $\mathrm{CD}^{+}$cells $\left(\mathrm{CD} 45 \mathrm{RO}^{+}\right.$, CD45RA- CD29 bright, LFA-1 $1^{\text {bright }}, \mathrm{CD} 44^{\text {bright }}$, LFA-3 ${ }^{\text {bright }}$, ICAM-1 ${ }^{+}$, L-selectin-) (Oppenheimer-Marks and Lipsky, 1995). These immunoreactive units are thought to be responsible for the initiation and "perpetuation" of RA.

Rheumatoid synovial endothelium expresses many cell-adhesion molecules, including ICAM-1, VCAM-1, Pselectin, and E-selectin (Oppenheimer-Marks and Lipsky, 1995). There has been a correlation in RA disease activity with soluble VCAM-1, but not ICAM-1, levels, despite the fact that ICAM-1 is the most intensely and broadly expressed adhesion molecule on RA endothelium (Pitzalis et al., 1994; Oppenheimer-Marks and Lipsky, 1995). Therapeutic trials in both animal models and humans have attempted to block the initiation or the continuation of the inflammatory synovial units by abrogating cellular adhesion with blocking peptides or antibodies (Oppenheimer-Marks and Lipsky, 1995). A recent open-label dose-escalation trial of an ICAM-1-specific $\mathrm{mAb}$ demonstrated significant long-term clinical improvement in patients with severe refractory RA receiving a five-day treatment (Kavanaugh et al., 1994). Further studies using ICAM-1-specific mAb in RA patients are currently under way.

\section{(B) PSORIASIS}

Psoriasis is a common idiopathic chronic inflammatory dermatologic disease that affects $1-2 \%$ of people and is characterized by erythematous, sharply demarcated papules, and rounded plaques with silvery scales. Important etiologic factors include genetic predisposition, infections (i.e., streptococcal), trauma, and other environmental factors. Immunohistochemical analysis of psoriatic lesions (plaques) reveals epidermal hyperproliferation, changes in the dermal microvasculature (including dilatation and tortuosity of the superficial dermal plexus, angiogenesis, and HEV formation), and an increased number of T-cells (reviewed in Griffiths, 1994; Lowe et al., 1995). Initially misidentified as a nonim- 
munologically mediated disease, secondary to the marked epidermal hyperproliferation, psoriasis is now known to be caused by abnormal microvasculature lymphocyte EC interactions.

In psoriatic lesions, the ECS in the papillary microvessels express increased levels of E-selectin, ICAM-1, and VCAM-1, compared with normal and noninvolved psoriatic skin (Griffiths, 1994; Wakita and Takigawa, 1994). Wakita and Takigawa (1994) analyzed psoriatic lesions at different phases of disease [initial (I). active (II), and resolving (III)], and found that E-selectin, ICAM-1, and VCAM-1 were most highly expressed in active phase II lesions. A recent study by Bonifati $e t$ al. (1995) demonstrated that soluble ICAM-1 levels in serum correlated with disease severity scores (psoriasis area and severity index) in psoriasis patients. The increase in ICAM-1, VCAM-1, and E-selectin levels correlates with the influx of $\mathrm{CD} 4+\mathrm{T}$-cells, suggesting that these molecules are important in the trafficking of T-cells into psoriatic lesions. Interestingly, as psoriatic lesions begin to involute and resolve, the CD8:CD4 T-cell ratio increases significantly (Wakita and Takigawa, 1994). The importance of this finding remains unknown.

Analysis of T-cells in psoriatic lesions has led to many interesting findings. Active psoriatic lesions contain an increase in $\mathrm{CD} 4^{+} \mathrm{CD} 45 \mathrm{RO}^{+} \mathrm{T}$-cells bearing activation markers, including HLA-DR and IL-2 receptor (CD25) (Griffiths, 1994). The influx of activated memory T-cells, preceding the characteristic hyperproliferation of the epidermal cells (Wakita and Takigawa, 1994), suggests that T-cells help initiate the inflammatory response. This T-cell-mediated inflammation is thought to result in the release of several cytokines and growth factors presumed to play a role in the pathogenesis of psoriatic plaques, including IFN- $\gamma$, TNF- $\alpha$, and two keratinocyte proliferative factors, IL-8 and transforming growth factor (Griffiths, 1994). T-cells that home to the skin are known to express the E selectin ligand CLA (see above) preferentially. It is likely that the T-cells found in active psoriatic lesions express CLA (Griffiths, 1994). Therefore, the CLA/E-selectin interaction is a prime target for immunopharmocologic therapy in psoriasis.

\section{(C) EXPERIMENTAL AUTOIMMUNE ENCEPHALOMYELITIS}

A third example of an autoimmmune disease involving lymphocyte-endothelial adhesive interactions is EAE, an experimental animal model that mimics multiple sclerosis (MS) (reviewed in Yednock et al., 1992). MS is a relapsing-remitting clinical disease that affects myelin-containing white-matter tracts within the CNS and often presents with optic neuritis or motor and sensory impairments (Francis et al, 1991). In both MS and EAE, lymphocytes and monocytes cross the blood-brain barrier, penetrating the brain parenchyma and damaging myelin
(Francis et al., 1991). EAE can be induced in animals either by priming with CNS proteins, such as myelin basic protein, or by adoptive transfer of CNS antigenspecific, activated T-cell clones. In EAE, the $\mathrm{CD}^{+}$memory T-lymphocytes gain access into the brain parenchyma by $\alpha 4 \beta 1$-mediated binding to VCAM-1 expressed on brain vessel endothelium (Yednock et al., 1992). In a rat model of EAE, the delayed (up to two days) administration of anti- $\alpha 4$ mAb prevented, or greatly attenuated, disease progression (Yednock et al., 1992). The investigators speculated that the antibody treatment blocked the entry of host monocytes and lymphocytes that normally would have infiltrated the brain in response to the inflammation induced by the T-cell clone. The fact that the antibody could be given after the introduction of the disease-initiating T-cell clone provides hope that similar treatments might work in MS patients, even after the onset of symptoms.

\section{(D) EFFECTS OF KNOWN THERAPEUTIC AGENTS ON ADHESION MOLECULES AND NEW THERAPIES}

The elucidation of adhesive cell-endothelial interactions in RA, psoriasis, and EAE has led to a better understanding of the therapeutic actions of many of the current medications used in immune-mediated diseases, and to the promise of new anti-adhesive therapies. We now know that many of the current anti-inflammatory and immunosuppressive medications, chosen empirically for their clinical efficacy, work by modulating lymphocyte-EC interactions. Corticosteroids, long a mainstay of treatment for RA, are now known to diminish the capacity of endothelium to up-regulate ICAM-1 and E-selectin expression after endotoxin or IL-1 treatment (Cronstein and Weissman, 1993). Colchicine, a phenanthrene derivative, has recently been found to diminish leukocyte rolling in the microvasculature, presumably due to a marked decrease in the expression of L-selectin on leukocytes and ICAM-1 on endothelium (Cronstein and Weissman, 1993). Last, methotrexate (an anti-metabolite) most likely induces an increase in the amount of adenosine, known to decrease $\beta 2$ integrin-mediated adhesion, released from injured cells (Cronstein and Weissman, 1993; Oppenheimer-Marks and Lipsky, 19951. Although vital to our current treatment armamentarium, the fact that these medications are unable to cure most immune-mediated diseases has fueled the search for a new class of anti-adhesion pharmaceutics.

Potential therapies currently being tested, in vitro and in vivo, include: mAbs, soluble receptors, peptide sequences able to block adhesion receptors, adhesionrecognition carbohydrates, and antisense oligonucleotides (Makgoba et al. 1992; Oppenheimer-Marks and Lipsky, 1995). Ultimately, ideal anti-adhesion therapies will have to demonstrate: (1) significant clinical benefit: (2) an effective and feasible dosing route; (3) sufficient 
specificity to allow other critical adhesion processes to continue; and (4) a low side-effect profile (Makgoba et al., 1992). Given the multitude of different immune-mediated diseases (acute and chronic) and the many different classes of adhesion molecules involved, it can be expected that several different therapeutic de-adhesive agents and combinations will need to be utilized.

\section{ACKNOWLEDGMENTS}

Research in Dr. Shimizu's laboratory is supported in part by grants from the NIH. Y.S. is the Harry Kay Professor of Cancer Research at the University of Minnesota.

\section{REFERENCES}

Adamthwaite D, Cooley MA (1994). CD8 ${ }^{+}$T-cell subsets defined by expression of $C D 45$ isoforms differ in their capacity to produce IL-2, IFN- $\beta$ and TNF- $\alpha$. Immunology 81:253-260.

Ager A (1994). Lymphocyte recirculation and homing. roles of adhesion molecules and chemoattractants. Trends Cell Biol 4:326-333

Ager A, Humphries MJ (1990). Use of synthetic peptides to probe lymphocyte-high endothelial cell interactions. Lymphocytes recognize a ligand on the endothelial surface which contains the CS1 adhesion motif. Int Immunol 2:921-928.

Airas L, Hellman J, Salmi M, Bono P, Puurunen T, Smith DI, et al. (1995). CD73 is involved in lymphocyte binding to the endothelium: characterization of lymphocyte-vascular adhesion protein 2 identifies it as CD73. J Exp Med 182:1603-1608.

Alon R, Cahalon L, Hershkoviz R, Elbaz D, Reizis B, Wallach $D$, et al. (1994). TNF- $\alpha$ binds to the N-terminal domain of fibronectin and augments the $\beta_{1}$-integrinmediated adhesion of $\mathrm{CD} 4^{+} \mathrm{T}$ lymphocytes to the glycoprotein. I Immunol 152:1304-1313

Alon R, Hammer DA, Springer TA (1995). Lifetime of the P-selectin-carbohydrate bond and its response to tensile force in hydrodynamic flow. Nature 374:539-542

Altevogt P, Hubbe M, Ruppert M, Lohr I, Von Hoegen P, Sammar $M$, et al. (1995). The $\alpha 4$ integrin chain is a ligand for $\alpha 4 \beta 7$ and $\alpha 4 \beta 1$. J Exp Med 182:345-355.

Arbones ML, Ord DC, Ley K, Ratech H, Maynard-Curry C, Otten G, et al. (1994). Lymphocyte homing and leukocyte rolling and migration are impaired in L-selectindeficient mice. Immunity 1:247-260.

Babi LFS, Moser R, Soler MTP, Picker LJ, Blaser K, Hauser $C$ (1995). Migration of skin-homing T-cells across cytokine-activated human endothelial cell layers involves interaction of the cutaneous lymphocyteassociated antigen (CLA), the very late antigen-4 (VLA-4), and the lymphocyte function-associated antigen-1 (LFA-1). J Immunol 154:1543-1550.

Bargatze RF, Butcher EC ( 1993 ). Rapid G protein-regulat- ed activation event involved in lymphocyte binding to high endothelial venules. I Exp Med 178:367-372.

Bargatze RF, Jutila MA, Butcher EC (1995). Distinct roles of L-selectin and integrin $\alpha 4 \beta 7$ in lymphocyte homing to Peyer's patch-HEV in situ: the multistep model confirmed and refined. Immunity 3:99-108.

Baumhueter S, Dybdal N, Kyle C, Lasky LA (1994). Global vascular expression of murine CD34, a sialomucin-like endothelial ligand for L-selectin. Blood 84:2554-2565.

Bell EB, Sparshott SM (1990). Interconversion of CD45R subsets of CD4 T-cells in vivo. Nature 348: 163-166.

Berg EL, Yoshino T, Rott LS, Robinson MK, Warnock RA, Kishimoto TK, et al. (1991). The cutaneous lymphocyte antigen is a skin lymphocyte homing receptor for the vascular lectin endothelial cell-leukocyte adhesion molecule 1. J Exp Med 174:1461-1466.

Berg EL, McEvoy LM, Berlin C, Bargatze RF, Butcher EC (1993). L-selectin-mediated lymphocyte rolling on MAdCAM-1. Nature 366:695-698.

Berlin C, Berg EL, Briskin MJ, Andrew DP, Kilshaw PI, Holzmann B, et al. (1993). $\alpha 4 \beta 7$ integrin mediates lymphocyte binding to the mucosal vascular addressin MAdCAM-1. Cell 74:185-195.

Berlin C, Bargatze RF, Campbell JI, Von Andrian UH, Szabo MC, Hasslen SR, et al. (1995). $\alpha 4$ integrins mediate lymphocyte attachment and rolling under physiologic flow. Cell 80:413-422

Bevilacqua MP (1993). Endothelial-leukocyte adhesion molecules. Ann Rev Immunol 11:767-804

Bird IN, Spragg IH, Ager A, Matthews N (1993). Studies of lymphocyte transendothelial migration: analysis of migrated cell phenotypes with regard to CD31 (PECAM1), CD45RA and CD45RO. Immunology 80:553-560.

Bonifati C, Trento E, Carducci M, Sacerdoti G, Mussi A, Fazio $M$, et al. (1995). Soluble E-selectin and soluble tumor necrosis factor receptor $(60 \mathrm{kD})$ serum levels in patients with psoriasis. Dermatology 190:128-131.

Boudreau N, Sympson CJ, Werb Z, Bissell MJ (1995). Suppression of ICE and apoptosis in mammary epithelial cells by extracellular matrix. Science 267:891-893

Brady HR, Spertini O, Jimenez W, Brenner BM, Marsden PA, Tedder TF (1992). Neutrophils, monocytes, and lymphocytes bind to cytokine-activated kidney glomerular endothelial cells through L-selectin (LAM-1) in vitro. J Immunol 149:2437-2444.

Brando C. Shevach EM (1995). Engagement of the vitronectin receptor $(\alpha \mathrm{v} \beta 3)$ on murine T-cells stimulates tyrosine phosphorylation of a $115-k D a$ protein. I Immunol 154:2005-2011.

Brezinschek RI, Lipsky PE, Galea P, Vita R, OppenheimerMarks N (1995). Phenotypic characterization of CD4 ${ }^{+}$ T-cells that exhibit a transendothelial migratory capacity. J Immunol 154:3062-3077

Brustein M, Kraal G, Mebius RE, Watson SR (1992). Identification of a soluble form of a ligand for the lym- 
phocyte homing receptor. I Exp Med 176:1415-1419.

Butcher EC (1993). Specificity of leukocyte-endothelial interactions and diapedesis: physiologic and therapeutic implications of an active decision process. Res Immunol 144:695-698.

Camp RL, Scheynius A, Johansson C, Puré E (1993). CD44 is necessary for optimal contact allergic responses but is not required for normal leukocyte extravasation. I Exp Med 178:497-507.

Campanero MR, Sánchez-Mateos P. Del Pozo MA, Sánchez-Madrid F (1994). ICAM-3 regulates lymphocyte morphology and integrin-mediated T-cell interaction with endothelial cell and extracellular matrix ligands. I Cell Biol 127:867-878.

Carlos TM. Harlan IM (1994). Leukocyte-endothelial adhesion molecules. Blood 84:2068-2101.

Carr MW, Roth S1, Luther E, Rose SS, Springer TA (1994). Monocyte chemoattractant protein 1 acts as a T-lymphocyte chemoattractant. Proc Natl Acad Sci USA 91:3652-3656.

Cassell D, Schwartz RH (1994). A quantitative analysis of antigen-presenting cell function: activated $B$ cells stimulate naïve CD4 T-cells but are inferior to dendritic cells in providing costimulation. I Exp Med 180 1829- 1840 .

Cepek KL. Parker CM. Madara JL. Brenner MB (1993). Integrin $\alpha^{\mathrm{E}} \beta_{7}$ mediates adhesion of $\mathrm{T}$ lymphocytes to epithelial cells. I Immunol 150:3459-3470.

Cepek KL. Shaw SK, Parker CM, Russell GJ, Morrow IS, Rimm DL, et al. (1994). Adhesion between epithelial cells and $T$ lymphocytes mediated by E-cadherin and the $\alpha^{E} \beta_{7}$ integrin. Nature 372:190-193.

Cerottini IC MacDonald HR (1989). The cellular basis of T-cell memory. Ann Rev Immunol 7:77-89

Chan BMC, Wong IGP, Rao A, Hemler ME (1991). T-cell receptor-dependent, antigen-specific stimulation of a murine $\mathrm{T}$ cell clone induces a transient. VLA protein-mediated binding to extracellular matrix. I Immunol 147:398-404.

Chang AC, Salomon DR, Wadsworth S, Hong M-JP, Mojcik CF. Otto $S$. et al. (1995), $\alpha_{3} \beta_{1}$ and $\alpha_{6} \beta_{1}$ integrins mediate laminin/merosin binding and function as costimulatory molecules for human thymocyte proliferation. I Immunol 154:500-510

Clark EA, Brugge IS (1995). Integrins and signal transduction pathways: the road taken. Science 268:233-239.

cronstein BN. Weissman G (1993). The adhesion molecules in inflammation. Arthr Rheum 36:147-157.

Damle NK, Klussman K, Leytze G, Myrdal S, Aruffo A, Ledbetter $\mid A$, et al (1994). Costimulation of $T$ lymphocytes with integrin ligands intercellular adhesion molecule-1 or vascular cell adhesion molecule-1 induces functional expression of CTLA-4, a second receptor for B7 I Immunol 152:2686-2697.

Danilenko DM, Rossitto PV, Van der Vieren M, Le Trong $H$ MCDonough SP, Affolter VK, et al (1995). A novel canine leukointegrin, $\alpha_{d} \beta_{2}$, is expressed by specific macrophage subpopulations in tissue and a minor CD8 ${ }^{+}$lymphocyte subpopulation in peripheral blood I Immunol 155:35-44

Davis LS, Oppenheimer-Marks N, Bednarczyk IL, McIntyre BW, Lipsky PE (1990). Fibronectin promotes proliferation of naive and memory T-cells by signalling through both VLA-4 and VLA-5 integrin molecules. I Immunol 145:785-793.

De Fougerolles AR, Springer TA (1992). Intercellular adhesion molecule 3, a third adhesion counter-receptor for lymphocyte function-associated molecule 1 on resting lymphocytes. J Exp Med 175:185-190.

Diamond MS, Springer TA (1994). The dynamic regulation of integrin adhesiveness. Curr Biol 4:506-517.

Dustin ML, Rothlein R, Bhan AK, Dinarello CA, Springer TA (1986). Induction by IL $I$ and interferon- $\beta$ : tissue distribution, biochemistry, and function of a natura! adherence molecule (ICAM-1). I Immunol 137:245-254.

Easter DW, Hoyt DB, Ozkan AN (1988). Immunosuppression by a peptide from the gelatin binding domain of human fibronectin. I Surg Res 45:370-375

Elices M). Tsai V, Strahl D, Goel AS, Tollefson V, Arrhenius $T$, et al. (1994). Expression and functional significance of alternatively spliced CS1 fibronectin in rheumatoid arthritis microvasculature. I Clin invest 93:405-416.

Fan S-T, Mackman N, Cui M-Z, Edgington TS (1995). Integrin regulation of an inflammatory effector gene: direct induction of the tissue factor promoter by engagement of $\beta 1$ or $\alpha 4$ integrin chains. I Immunol 154:3266-3274.

Faull RI, Kovach NL, Harlan IM. Ginsberg MH (1994). Stimulation of integrin-mediated adhesion of Tymphocytes and monocytes: two mechanisms with divergent biological consequences. I Exp Med 179:1307-1316.

Ferguson TA, Kupper TS (1993). Antigen-independent processes in antigen-specific immunity: a role for $\alpha 4$ integrin. I Immunol 150:1172-1182

Ferguson TA, Mizutani H, Kupper TS (1991). Two integrinbinding peptides abrogate T-cell-mediated immune responses in vivo. Proc Natl Acad Sci USA 88:8072-8076.

Francis CS, Antel JP. Duquette P (1991). Inflammatory demyelinating diseases of the central nervous system. In: Neurology in clinical practice. Bradley WG, Daroff RB, Fenichel GM, Marsden CD, editors. Boston: Butterworth-Heineman, pp. 1134-1166.

Freedman AS, Rhynhart K, Nojima Y, Svahn 1, Eliseo L. Benjamin CD, et al. (1993) Stimulation of protein tyrosine phosphorylation in human $\mathrm{B}$ cells after ligation of the BI integrin VLA-4. I Immunol 150:1645-1652.

Friedl P, Noble PB, Zanker KS (1995). T lymphocyte locomotion in a three-dimensional collagen matrix. Expression and function of cell adhesion molecules. I Immunol 154:4973-4985.

Fuịii Y, Okumura M, Inada K, Nakahara K (1992). Reversal of CD45R isoform switching in $\mathrm{CD}^{+}$T-cells. Cell 
Immunol 139:176-184.

Gilat D, Hershkoviz R, Mekori YA, Vlodavsky I, Lider O (1994). Regulation of adhesion of $\mathrm{CD}^{+} \mathrm{T}$ lymphocytes to intact or heparanase-treated subendothelial extracellular matrix by diffusible or anchored RANTES and MIP-1ß. J Immunol 153:4899-4906.

Gilat D, Hershkoviz R, Goldkorn I, Cahalon L, Korner G, Vlodavsky l, et al. (1995). Molecular behavior adapts to context: heparanase functions as an extracellular matrixdegarding enzyme or as a T-cell adhesion molecule. depending on the local pH. J Exp Med 181:1929-1934.

Godfrey HP (1990). T-cell fibronectin: an unexpected inflammatory lymphokine. Lymphokine Res 9:435-447.

Goldman R, Harvey 1, Hogg N (1992). VLA-2 is the integrin used as a collagen receptor by leukocytes. Eur J Immunol 22:1109-1114.

Griffiths CE (1994). Cutaneous leukocyte trafficking and psoriasis. Arch Dermatol 130:494-499.

Groux H, Huet S, Valentin H, Pham D, Bernard A (1989). Suppressor effects and cyclic AMP accumulation by the CD29 molecule of CD4+ lymphocytes. Nature 339:152-154.

Hamann A, Andrew DP, Jablonski-Westrich D, Holzmann B, Butcher EC (1994). Role of $\alpha_{4}$-integrins in lymphocyte homing to mucosal tissues in vivo. I Immunol 152:3282-3293.

Harlan J (1993). Leukocyte adhesion deficiency syndrome: insights into the molecular basis of leukocyte emigration. Clin Immunol Immunopathol 67:S16-S24.

Hauzenberger D, Sundqvist KG (1993). Fibronectin at the lymphocyte surface. Evidence for activation-dependent binding to VLA4 and VLA5 integrins. Scand I Immunol 37:87-95.

Hauzenberger D, Klominek J, Sundqvist K-G (1994). Functional specialization of fibronectin-binding $\beta_{1}$ integrins in $\mathrm{T}$ lymphocyte migration. I Immunol 153:960-971.

Hemler ME (1990). VLA proteins in the integrin family: structures, functions, and their role on leukocytes. Ann Rev Immunol 8:365-400.

Hemmerich S, Bertozzi CR, Leffler H, Rosen SD (1994). Identification of the sulfated monosaccharides of GlyCAM-1, an endothelial-derived ligand for Lselectin. Biochemistry 33:4820-4829.

Hershkoviz R, Alon R, Gilat D, Lider O (1992). Activated T lymphocytes and macrophages secrete fibronectin which strongly supports cell adhesion. Cell Immunol 141:352-361.

Hershkoviz R, Cahalon L, Gilat D, Miron S, Miller A, Lider O (1993). Physically damaged extracellular matrix induces TNF- $\alpha$ secretion by interacting resting $C D 4^{+}$ T-cells and macrophages. Scand J Immunol 37:111-115.

Hershkoviz R, Cahalon L, Miron S, Alon R, Sapir T, Akiyama SK, et al. (1994a). TNF- $\alpha$ associated with fibronectin enhances phorbol myristate acetate- or antigen-mediated integrin-dependent adhesion of $\mathrm{CD} 4^{+}$T-cells via protein tyrosine phosphorylation. I Immunol 153:554-565.

Hershkoviz R, Greenspoon N, Mekori YA, Hadari R, Alon $R$, Kapustina $G$, et al. (1994b). Inhibition of $C D 4^{+} \mathrm{T}$ lymphocyte binding to fibronectin and immune-cell accumulation in inflammatory sites by non-peptidic mimetics of Arg-Gly-Asp. Clin Exp Immunol 95:270-276.

Hession C, Tizard R, Vassallo C, Schiffer SB, Goff D, Moy $P$, et al. (I 991). Cloning of an alternate form of vascular cell adhesion molecule-1 (VCAM-1). I Biol Chem 266:6682-6685.

Hines KL, Kulkarni AB, McCarthy JB, Tian H, Ward IM, Christ M, et al. (1994). Synthetic fibronectin peptides interrupt inflammatory cell infiltration in transforming growth factor $\beta 1$ knockout mice. Proc Natl Acad Sci USA 91:5187-5191.

Horuk R, Wang Z, Peiper SC, Hesselgesser I (1994). Identification and characterization of a promiscuous chemokine-binding protein in a human erythroleukemic cell line. J Biol Chem 269:17730-17733.

Hou S, Doherty PC (1993). Partitioning of responder $\mathrm{CD} 8^{+}$T-cells in lymph node and lung of mice with Sendai virus pneumonia by LECAM-1 and CD45RB phenotype. J Immunol 150:5494-5500.

Hourihan H, Allen TD, Ager A (1993). Lymphocyte migration across high endothelium is associated with increases in $\alpha_{4} \beta_{1}$ integrin (VLA-4) affinity. J Cell Sci 104:1049-1059.

Hruska KA, Rolnick F, Huskey M, Alvarez U, Cheresh D (1995). Engagement of the osteoclast integrin $\alpha_{v} \beta_{3}$ by osteopontin stimulates phosphatidylinositol 3hydroxyl kinase activity. Endocrinology 136:2984-2992.

Huhtala P, Humphries MJ, McCarthy JB, Tremble PM, Werb Z, Damsky CH (1995). Cooperative signaling by $\alpha 5 \beta 1$ and $\alpha 4 \beta 1$ integrins regulates metalloproteinase gene expression in fibroblasts adhering to fibronectin. J Cell Biol 129:867-879

Huleatt JW, Lefrançois L (1995). Antigen-driven induction of CD11c on intestinal intraepithelial lymphocytes and $\mathrm{CD} 8^{+}$T-cells in vivo. J Immunol 154:5684-5693.

Hynes RO (1992). Integrins: versatility, modulation, and signaling in cell adhesion. Cell 69:11-25

Hynes RO (1994). The impact of molecular biology on models for cell adhesion. BioEssays 16:663-669

Imai Y, Lasky LA, Rosen SD (1993). Sulphation requirement for GlyCAM-1, an endothelial ligand for Lselectin. Nature 361:555-557.

Issekutz TB (1993). The contributions of integrins to leukocyte infiltration in inflamed tissues. Curr Top Microbiol Immunol 184:177-185.

Jalkanen S, Salmi M (1993). Vascular adhesion protein-1 (VAP-1): a new adhesion molecule recruiting lymphocytes to sites of inflammation. Res Immunol 144:746-749. Jones DA, McIntire LV, Smith CW, Picker LI (1994). A two- 
step adhesion cascade for T-cell/endothelial cell interactions under flow conditions. I Clin Invest 94:2443-2450.

Iones EY, Harlos K, Bottomley MJ, Robinson RC, Driscoll PC, Edwards RM, et al. (1995). Crystal structure of an integrin-binding fragment of vascular cell adhesion molecule- 1 at $1.8 \AA$ resolution. Nature 373:539-544.

Kamata T. Puzon W, Takada Y (1995). Identification of putative ligand-binding sites of the integrin $\alpha 4 \beta 1$ (VLA-4. CD49d/CD29). Biochem 1 305:945-951.

Kanner SB. Aruffo A, Chan P-Y (1994). Lymphocyte antigen receptor activation of a focal adhesion kinaserelated tyrosine kinase substrate. Proc Natl Acad Sci USA 91:10484-10487.

Kansas GS, Ley K, Munro IM. Tedder TF (1993). Regulation of leukocyte rolling and adhesion to high endothelial venules through the cytoplasmic domain of L-selectin. I Exp Med 177:833-838.

Kapeller R. Cantley LC (1994). Phosphatidylinositol 3kinase. BioEssays 16:565-576

Karecla PI. Bowden SI. Green SI, Kilshaw PJ (1995). Recognition of E-cadherin on epithelial cells by the mucosal T-cell integrin $\alpha_{M 290} \beta 7$ (aEß37). Eur ) Immunol 25:852-856

Kavanaugh AF, Davis LS, Nichols LA, Norris SH, Rothlein R, Scharschmidt LA, et al. (1994). Treatment of refractory rheumatoid arthritis with a monoclonal antibody to intercellular adhesion molecule 1. Arthr Rheum 37:992-999.

Kern F, Döcke WD, Reinke P, Volk HD (1994). Discordant expression of LFA-1,VLA-4 $\alpha, V L A-\beta 1, C D 45 R O$ and CD28 on T-cell subsets: evidence for multiple subsets of "memory" T-cells. Int Arch Allergy Immunol 104:17-26.

Kilger G. Needham LA, Nielsen P], Clements ], Vestweber D. Holzmann B (1995). Differential regulation of $\alpha_{4}$ integrin-dependent binding to domains 1 and 4 of vascular cell adhesion molecule-1. I Biol Chem 270 5979-5984.

Klingemann HG, Tsoi MS, Storb R (1986). Fibronectin restores defective in vitro proliferation of patients lymphocytes after marrow grafting. Transplantation 42:412-417.

Koopman G. Griffioen AW, Ponta H, Herrlich P, Van den Berg F, Manten-Horst E, et al. (1993). CD44 splice variants: expression on lymphocytes and in neoplasia. Res Immunol 144:750-762.

Koopman G, Keehnen RMI, Lindhout E, Newman W, Shimizu $Y$, van Seventer GA, et al. (1994). Adhesion through the LFA1 (CDI la/CD I8)-ICAM-1 (CD54) and the VLA-4 (CD49d)VCAM-1 (CD 106) pathways prevents apoptosis of germinal center B cells. I Immunol 152:3760-3767.

Laffón A, García-Vicuña R. Humbría A, Postigo AA, Corbí AL. De Landázuri MO, et al. (1991). Upregulated expression and function of VLA-4 fibronectin receptors on human activated T-cells in rheumatoid arthritis. I Clin Invest 88:546-552
Lasky LA (1995). Selectin-carbohydrate interactions and the initiation of the inflammatory response. Ann Rev Biochem 64:113-139.

Lawrence MB, Springer TA (1991). Leukocytes roll on a selectin at physiologic flow rates: distinction from and prerequisite for adhesion through integrins. Cell 65:859-873

Lawrence MB, Berg EL, Butcher EC, Springer TA (1995). Rolling of lymphocytes and neutrophils on peripheral node addressin and subsequent arrest on ICAM- 1 in shear flow. Eur I Immunol 25:1025-1031.

Lepault F, Gagnerault M-C, Faveeuw C, Boitard C (1994). Recirculation, phenotype and functions of lymphocytes in mice treated with monoclonal antibody MEL14. Eur J Immunol 24:3106-3112

Leppert D, Waubant E, Galardy R, Bunnett NW, Hauser SL (1995). T-cell gelatinases mediate basement membrane transmigration in vitro. I Immunol 154:4379-4389.

Lesley J, Hyman R, Kincade PW (1993). CD44 and its interaction with extracellular matrix. Adv Immunol 54:271-335.

Lesley I. Howes N, Perschl A. Hyman R (1994). Hyaluronan binding function of CD44 is transiently activated on T-cells during an in vivo immune response. I Exp Med 180:383-387

Ley K, Tedder TF, Kansas GS (1993). L-selectin can mediate leukocyte rolling in untreated mesenteric venules in vivo independent of E- or P-selectin. Blood 82:1632-1638.

Lider O, Mekori YA, Miller T, Bar-Tana R, Vlodavsky I, Baharav E, et al. (1990). Inhibition of $T$ lymphocyte heparanase by heparin prevents $\mathrm{T}$-cell migration and T-cell-mediated immunity. Eur I Immunol 20:493-499.

Lo SK, Lee S, Ramos RA, Lobb R, Rosa M. Chi-Rosso G, et al. (1991). Endothelial-leukocyte adhesion molecule 1 stimulates the adhesive activity of leukocyte integrin CR3 (CD 1 lb/CD 18, Mac-1, $\alpha, \beta_{2}$ ) on human neutrophils. I Exp Med 173:1493-1500.

Lollo BA, Chan KWH, Hanson EM. Moy VT, Brian AA (1993). Direct evidence for two affinity states for lymphocyte function-associated antigen 1 on activated Tcells. I Biol Chem 268:21693-21700

Lopez Rodriguez C, Nueda A, Grospierre B. Sanchez-Madrid F, Fischer A, Springer TA, et al (1993). Characterization of two new CD 18 alleles causing severe leukocyte adhesion deficiency. Eur I Immunol 23:2792-2798

Lowe PM, Lee ML, lackson Cl, To SST, Cooper AJ Schrieber L (1995). The endothelium in psoriasis. $\mathrm{Br}$. Dermatol 132:497-505

Luscinskas FW, Ding H, Lichtman AH (1995). P-selectin and vascular cell adhesion molecule 1 mediate rolling and arrest, respectively, of $C D 4^{+} T$ lymphocytes on tumor necrosis factor $\beta$-activated vascular endothelium under flow. I Exp Med 181:1179-1186.

Mackay CR (1992). Migration pathways and immunologic memory among $\mathrm{T}$ lymphocytes. Semin Immunol 4:51-58. 
Mackay CR (1994). The concept of memory T cells. In: Handbook of $\mathrm{T}$ and B lymphocytes. Snow EC, editor. San Diego: Academic Press, pp. 159-177.

Makgoba MW, Bernard A, Sanders ME (1992). Cell adhesion/signalling: biology and clinical applications. Eur I Clin Invest 22:443-453.

Marlin SD, Springer TA (1987). Purified intercellular adhesion molecule-1 (ICAM-1) is a ligand for lymphocyte function-associated antigen-1 (LFA-1). Cell 51:813-819

Matsuyama T, Yamada A, Kay J, Yamada KM, Akiyama SK, Schlossman SF, et al. (1989). Activation of CD4 cells by fibronectin and anti-CD3 antibody. A synergistic effect mediated by the VLA-5 fibronectin receptor complex. J Exp Med 170:1133-1148.

McCourt PAG, Ek B, Forsberg N, Gustafson S (1994). Intercellular adhesion molecule-1 is a cell surface receptor for hyaluronan. J Biol Chem 269:30081-30084.

McEver RP (1994). Selectins. Curr Opin Immunol 6:75-84.

Metlay JP, Pure E, Steinman RM (1989). Control of the immune response at the level of antigen presenting cells: a comparison of the function of dendritic cells and B lymphocytes. Adv Immunol 47:45-116.

Mignati P, Rifkin DB (1993). Biology and biochemistry of proteinases in tumor invasion. Physiol Rev 73:161-195.

Mobley JL, Dailey MO (1992). Regulation of adhesion molecule expression by CD8 T-cells in vivo. I. Differential regulation of gp90 ${ }^{\text {MEL-14 }}$ (LECAM-1), Pgp1. LFA-1, and VLA-4 $\beta$ during the differentiation of cytotoxic $\mathrm{T}$ lymphocytes induced by allografts. I Immunol 148:2348-2356.

Mobley IL, Reynolds PJ, Shimizu Y (1993). Regulatory mechanisms underlying T-cell integrin receptor function. Semin Immunol 5:227-236.

Mobley JL, Rigby SM, Dailey MO (1994). Regulation of adhesion molecule expression by CD8 T-cells in vivo: II. Expression of L-selectin (CD62L) by memory cytolytic T-cells responding to minor histocompatibility antigens. J Immunol 153:5443-5452.

Morino N, Mimura T, Hamasaki K, Tobe K, Ueki K, Kikuchi $K$, et al. (1995). Matrix/integrin interaction activates the mitogen-activated protein kinase, p44 erk-1 and p42erk-2. I Biol Chem 270:269-273.

Mosher DF (1990). Physiology of thrombospondin. Ann Rev Med 41:85-97.

Moulder K, Roberts K, Shevach EM, Coligan JE (1991). The mouse vitronectin receptor is a T-cell activation antigen. J Exp Med 173:343-347.

Moy P, Lobb R, Tizard R, Olson D, Hession C (1993). Cloning of an inflammation-specific phosphatidyl inositol-linked form of murine vascular cell adhesion molecule-1. J Biol Chem 268:8835-8841.

Nojima Y, Rothstein DM. Sugita K, Schlossman SF, Morimoto C (1992). Ligation of VLA-4 on T-cells stimulates tyrosine phosphorylation of a $105-k D$ protein. I
Exp Med 175:1045-1053

Nojima Y, Tachibana K, Sato T, Schlossman SF, Morimoto C (1995). Focal adhesion kinase ( $\mathrm{ppl} 25^{\mathrm{FAK}}$ ) is tyrosine phosphorylated after engagement of $\alpha 4 \beta 1$ and $\alpha 5 \beta 1$ integrins on human T-lymphoblastic cells. Cell Immunol 161:8-13.

Oppenheimer-Marks N, Lipsky PE (1995). Leukocyte adhesion and leukocyte traffic in rheumatoid arthritis. In: Mechanisms and models in rheumatoid arthritis. Henderson B, Edwards ICW, Pettipher ER, editors. London: Academic Press Ltd., pp. 221-239.

Osborn L, Hession C, Tizard R, Vassallo C, Luhowskyj S, Chi-Rosso $G$, et al. (1989). Direct expression cloning of vascular cell adhesion molecule 1 , a cytokine-induced endothelial protein that binds to lymphocytes. Cell 59:1203-1211.

Ostergaard HL, Ma EA (1995). Fibronectin induces phosphorylation of a $120-\mathrm{kDa}$ protein and synergizes with the T-cell receptor to activate cytotoxic T-cell clones. Eur I Immunol 25:252-256.

Pardi R, Inverardi L, Bender IR (1992). Regulatory mechanisms in leukocyte adhesion: flexible receptors for sophisticated travelers. Immunol Today 13:224-230.

Parker CM, Cepek KL, Russell GJ, Shaw SK, Posnett DN, Schwarting $R$, et al. (1992). A family of $\beta_{7}$ integrins on human mucosal lymphocytes. Proc Natl Acad Sci USA 89:1924-1928.

Patel DI, Gumbiner BM (1995). Zipping together a cell adhesion interface. Nature 374:306-307.

Piali L, Hammel P, Uherek C, Bachmann F, Gisler RH, Dunon D, et al. (1995). CD31/PECAM-1 is a ligand for $\alpha_{v} \beta_{3}$ integrin involved in adhesion of leukocytes to endothelium. I Cell Biol 130:451-460.

Picker LJ (1994). Control of lymphocyte homing. Curr Opin Immunol 6:394-406.

Picker LJ, Butcher EC (1992). Physiological and molecular mechanisms of lymphocyte homing. Ann Rev Immunol 10:561-591

Picker LJ, Nakache M, Butcher EC (1989). Monoclonal antibodies to human lymphocyte homing receptors define a novel class of adhesion molecules on diverse cell types. I Cell Biol 109:927-937.

Picker LJ, Warnock RA, Burns AR, Doerschuk CM, Berg EL, Butcher EC (1991). The neutrophil selectin LECAM-1 presents carbohydrate ligands to the vascular selectins ELAM-1 and GMP-140. Cell 66:92 I-933.

Picker LJ, Treer IR, Ferguson-Darnell B, Collins PA, Buck D. Terstappen LWMM (1993a). Control of lymphocyte recirculation in man: I. Differential regulation of the peripheral lymph node homing receptor $L$-selectin on T-cells during the virgin to memory cell transition. I Immunol 150:1105-1121.

Picker LJ, Treer JR, Ferguson-Darnell B, Collins PA, Bergstresser PR, Terstappen LWMM (1993b). Control of lymphocyte recirculation in man: II. Differential regulation of the cutaneous lymphocyte-associated 
antigen, a tissue-selective homing receptor for skinhoming T-cells. J Immunol 150:1122-1136

Pietschmann P. Cush II. Lipsky PE, Oppenheimer-Marks $\mathrm{N}$ (1992). Identification of subsets of human T-cells capable of enhanced transendothelial migration. I Immunol 149:1170-1178

Pitzalis C. Kingsley G, Panayi G (1994). Adhesion molecules in rheumatoid arthritis: role in the pathogenesis and prospects for therapy. Ann Rheum Dis 53:287-288.

Pober IS. Bevilacqua MP, Mendrick DL, Lapierre LA, Fiers W. Gimbrone MA (1986). Two distinct monokines, interleukin I and tumor necrosis factor, each independently induce biosynthesis and transient expression of the same antigen on the surface of cultured human vascular endothelial cells. I Immunol 136:1680-1687.

Price TH, Ochs D, Gershoni-Baruch RG (1994). In vivo neutrophil and lymphocyte function studies in a patient with leukocyte adhesion deficiency type II. Blood 84:1635-1639

Rabinowich $H$, Lin W, Manciulea M, Herberman RB, Whiteside TL (1995). Induction of protein tyrosine phosphorylation in human natural killer cells by triggering via $\alpha_{4} \beta_{1}$ or $\alpha_{5} \beta_{1}$ integrins. Blood 85:1858-1864.

Richardson A, Parsons IT (1995). Signal transduction through integrins: a central role for focal adhesion kinase. BioEssays 17:229-236.

Rodriguez RM. Pitzalis C, Kingsley GH, Henderson E, Humphries MJ, Panayi GS (1992). T lymphocyte adhesion to fibronectin ( $F N$ ): a possible mechanism for Tcell accumulation in the rheumatoid joint. Clin Exp Immunol 89:439-445.

Romanic AM. Madri IA (1994). The induction of $72-k D$ gelatinase in T-cells upon adhesion to endothelial cells is VCAM-1 dependent. I Cell Biol 125:1165-1178.

Rüegg CR Chiquet-Ehrismann R, Alkan SS (1989). Tenascin, an extracellular matrix protein, exerts immunomodulatory activities. Proc Natl Acad Sci USA 86:7437-7441

Rybski IA, Lause DB, Reese AC (1989). Effect of fibronectin on antigen-induced lymphoproliferation and antibody synthesis in rats. I Leukoc Biol 45:35-45.

Salomon DR, Mojcik CF, Chang AC, Wadsworth S, Adams $D H$, Coligan IE, et al. (1994). Constitutive activation of integrin $\alpha 4 \beta 1$ defines a unique stage of human thymocyte development. I Exp Med 179:1573-1584.

Saltini C. Hemler ME, Crystal RG (1988). T lymphocytes compartmentalized on the epithelial surface of the lower respiratory tract express the very late activation antigen complex VLA-1 Clin Immunol Immunopathol 46:221-233.

Sawada M. Nagamine I. Takeda K, Utsumi K, Kosugi A, Tatsumi $Y$, et al. (1992). Expression of VLA-4 on thymocytes: maturation stage-associated transition and its correlation with their capacity to adhere to thymic stromal cells. I Immunol 149:3517-3524.

Schaller MD. Parsons IT (1994). Focal adhesion kinase and associated proteins. Curr Opin Cell Biol 6:705-710. Schleiffenbaum B, Spertini O, Tedder TF (1992). Soluble $\mathrm{L}$-selectin is present in human plasma at high levels and retains functional activity. I Cell Biol 119:229-238

Seftor REB, Seftor EA, Gehlsen KR, Stetler-Stevenson WG, Brown PD, Ruoslahti E, et al. (1992). Role of the $\alpha v \beta 3$ integrin in human melanoma cell invasion. Proc Natl Acad Sci USA 89:1557-1561

Seltzer JL, Lee A-Y, Akers KT, Sudbeck B. Southon EA Wayner EA, et al (1994). Activation of 72-kDa type IV collagenase/gelatinase by normal fibroblasts in collagen lattices is mediated by integrin receptors but is not related to lattice contraction. Exp Cell Res 213:365-374.

Shapiro L, Fannon AM, Kwong PD, Thompson A. Lehman MS, Grubel G, et al. (1995). Structural basis of cell-cell adhesion by cadherins. Nature 374:327-337.

Shimizu Y, Shaw S (1991). Lymphocyte interactions with extracellular matrix. FASEB 1 5:2292-2299.

Shimizu Y, Shaw S (1993). Mucins in the mainstream Nature 366:630-631.

Shimizu Y, van Seventer GA, Horgan KJ. Shaw S (1990a). Roles of adhesion molecules in T-cell recognition: fundamental similarities between four integrins on resting human T-cells (LFA-1, VLA-4, VLA-5, VLA-6) in expression, binding, and costimulation. immunol Rev 114:109-143.

Shimizu Y, van Seventer GA, Horgan KJ. Shaw S (1990b). Costimulation of proliferative responses of resting CD4+ T-cells by the interaction of VLA- 4 and VLA- 5 with fibronectin or VLA-6 with laminin. I Immunol 145:59-67.

Shimizu Y, van Seventer GA, Horgan Kl, Shaw S (1990C). Regulated expression and binding of three VLA ( $\beta 1)$ integrin receptors on T-cells. Nature 345:250-253.

Shimizu Y, Shaw S, Graber N, Gopal TV, Horgan KI, van Seventer GA, et al. (1991). Activation-independent binding of human memory T-cells to adhesion molecule ELAM-1. Nature 349:799-802.

Simon SI, Burns AR, Taylor AD, Gopalan PK, Lynam EB Sklar LA, et al. (1995). L-selectin (CD62L) cross-linking signals neutrophil adhesive functions via the Mac-1 (CDIIb/CD18) $\beta_{2}$-integrin. I Immunol 155:1502-1514.

Smith CW, Kishimoto TK, Abbass O, Hughes B, Rothlein $R$, McIntire LV. et al. (1991). Chemotactic factors regulate lectin adhesion molecule 1 (LECAM-1)-dependent neutrophil adhesion to cytokine-stimulated endothelial cells in vitro. I Clin Invest 87.609-618

Spertini O, Kansas GS, Munro IM. Griffin ID, Tedder TF (1991a). Regulation of leukocyte migration by activation of the leukocyte adhesion molecule-1 (LAM-1) selectin. Nature 349:691-694.

Spertini O, Luscinskas FW, Kansas GS, Munro IM, Griffin JD, Gimbrone MA, et al. (1991b). Leukocyte adhesion molecule-1 (LAM-1) interacts with an inducible endothelial cell ligand to support leukocyte adhesion. I Immunol 147:2565-2573. 
Sprent J (1994). T and B memory cells. Cell 76:315-322.

Springer TA (1994). Traffic signals for lymphocyte recirculation and leukocyte emigration: the multistep paradigm. Cell 76:301-314.

Staunton DE, Dustin ML, Springer TA (1989). Functional cloning of ICAM-2, a cell adhesion ligand for LFA-1 homologous to ICAM-1. Nature 339:61-64.

Steinman L (1995). Escape from "Horror Autotoxicus": pathogenesis and treatment of autoimmune disease. Cell 80:7-10.

Steinman RM (1991). The dendritic cell system and its role in immunogenicity. Ann Rev Immunol 9:271-296.

Streeter PR, Rouse BTN, Butcher EC (1988). Immunohistologic and functional characterization of a vascular addressin involved in lymphocyte homing into peripheral lymph nodes. I Cell Biol 107:1853-1862.

Sturmhöfel K, Brando C, Martinon F, Shevach EM, Coligan IE (1995). Antigen-independent, integrinmediated T-cell activation. I Immunol 154:2104-2111.

Szekanecz Z, Humphries MI, Ager A (1992). Lymphocyte adhesion to high endothelium is mediated by two $\beta_{1}$ integrin receptors for fibronectin, $\alpha_{4} \beta_{1}$ and $\alpha_{5} \beta_{1}$. I Cell Sci 101:885-894.

Tanaka Y, Albelda SM, Horgan KJ, van Seventer GA, Shimizu Y, Newman W, et al. (1992). CD31 expressed on distinctive T-cell subsets is a preferential amplifier of B1 integrin-mediated adhesion. J Exp Med 176:245-253.

Tanaka Y, Adams DH, Hubscher S, Hirano H. Siebenlist U, Shaw S (1993a). T-cell adhesion induced by proteoglycan-immobilized cytokine MIP-1ß. Nature 361:79-82.

Tanaka Y, Adams DH, Shaw S (1993b). Proteoglycans on endothelial cells present adhesion-inducing cytokines to leukocytes. Immunol Today 14:111-115.

Tedder TF, Steeber DA, Chen A, Engel P (1995). The selectins: vascular adhesion molecules. FASEB I 9:866-873.

Ticchioni $M$, Deckert $M$, Bernard $G$, Calandra D, Breittmeyer J-P, Imbert $V$, et al. (1995). Comitogenic effects of very late activation antigens on CD3-stimulated human thymocytes: involvement of various tyrosine kinase pathways. I Immunol 154:1207-1215.

Tripp RA, Hou S, Doherty PC (1995). Temporal loss of the activated L-selectin-low phenotype for virus-specific CD8 ${ }^{+}$memory T-cells. I Immunol 154:5870-5875.

Ushiyama S, Laue TM, Moore KL, Erickson HP, McEver RP (1993). Structural and functional characterization of monomeric soluble P-selectin and comparison with membrane P-selectin. J Biol Chem 268:15229-15237.

Utsumi K, Sawada M, Narumiya S, Nagamine I, Sakata T, Iwagami $S$, et al. (1991). Adhesion of immature thymocytes to thymic stromal cells through fibronectin molecules and its significance for the induction of thymocyte differentiation. Proc Natl Acad Sci USA 88:5685-5689. van Seventer GA, Shimizu Y, Shaw S (1991). Roles of multiple accessory molecules in T-cell activation. Curr Opin Immunol 3:294-303.

Vennegoor CJGM, van de Wiel-van Kemenade E, Huijbens RJF, Sanchez-Madrid F, Melief CIM, Figdor CG (1992). Role of LFA-1 and VLA-4 in the adhesion of cloned normal and LFA-1 (CD11/CD18)-deficient Tcells to cultured endothelial cells: indication for a new adhesion pathway. I Immunol 148:1093-1101.

Verhagen AM, Kimpton WG, Nash AD (1995). Recirculation of cytolytic T-cells from a single lymph node during an immune response to allogeneic leukocytes. Transplantation 59:432-435.

Vlodavsky I, Eldor A, Haimovitz-Friedman A, Matzner Y, Ishai-Michaeli $R$, Lider $O$, et al. (1992). Expression of heparanase by platelets and circulating cells of the immune system: Possible involvement in diapedesis and extravasation. Invasion Metastasis 12:112-127.

Wakita H, Takigawa M (1994). E-selectin and vascular cell adhesion molecule-1 are critical for initial trafficking of helper-inducer/memory T-cells in psoriatic plaques. Arch Dermatol 130:457-463.

Washington EA, Keterelos M. Cahill RNP, Kimpton WG (1994). Differences in tissue-specific homing of $\alpha \beta$ and $\alpha \beta$ T-cells to gut and peripheral lymph nodes. Int Immunol 6:1891-1897.

Wilder RL (1993). Rheumatoid arthritis. A. Epidemiology, pathology, and pathogenesis. In: Primer on the rheumatic diseases. Shumacher HRJ, editor. Atlanta: The Arthritis Foundation, pp. 86-89.

Witherden DA, Abernathy NI, Kimpton WJ, Cahill RNP (1994). Changes in thymic export of L-selectin $+\alpha \beta$ and $\alpha \beta$ T-cells during fetal and postnatal development. Eur I Immunol 24:1234-1239.

Woessner IF (1991). Matrix metalloproteinases and their inhibitor in connective tissue remodeling. FASEB I 5:2145-2154.

Yabkowitz R, Dixit VM, Guo N, Roberts DD, Shimizu Y (1993). Activated T-cell adhesion to thrombospondin is mediated by the $\alpha 4 \beta 1$ (VLA-4) and $\alpha 5 \beta 1$ (VLA- 5 ) integrins. I Immunol 151:149-158.

Yamada A, Nikaido T, Nojima Y, Schlossman SF, Morimoto $C$ (1991). Activation of human CD4 $\mathrm{T}$ lymphocytes. Interaction of fibronectin with VLA-5 receptor on CD4 cells induces the AP-1 transcription factor. I Immunol 146:53-56.

Yednock TA, Cannon C, Fritz LC, Sanchez-Madrid F, Steinman L, Karin N ( 1992). Prevention of experimental autoimmune encephalomyelitis by antibodies against $\alpha 4 \beta 1$ integrin. Nature 356:63-66.

Young AJ, Hay IB, Mackay CR (1993). Lymphocyte recirculation and life span in vivo. Curr Top Microbiol immunol 184:161-173. 